\title{
Controle estrutural da borda sudeste da Bacia do Parnaíba, Nordeste do Brasil: relação com eventos geodinâmicos no Gondwana
}

\author{
Structural control of the southeastern border of the Parnaiba Basin,
} Northeastern Brazil: relationships with geodynamic events in Gondwana

\author{
Francisco Gabriel Ferreira de Lima¹, Emanuel Ferraz Jardim de Sá1,2 \\ 1 Programa de Pós-Graduação em Geodinâmica e Geofísica, Universidade Federal do Rio Grande do Norte - UFRN, \\ Campus Universitário, Lagoa Nova, Caixa Postal 1.596, CEP 59078-970, Natal, RN, BR (gabrielfleng@gmail.com) \\ 2Departamento de Geologia, UFRN, Natal, RN, BR (emanuel@ccet.ufrn.br)
}

Recebido em 31 de janeiro de 2017; aceito em 26 de maio de 2017

\begin{abstract}
Resumo
O limite sudeste da Bacia do Parnaíba (BPar), região fronteiriça aos Estados do Piauí, da Bahia e de Pernambuco (Nordeste do Brasil), é cartografado como uma não conformidade entre o Grupo Serra Grande (GSG, Siluriano) e o embasamento pré-cambriano. Todavia, essa borda é caracterizada por uma expressiva orientação NE, paralela ao Lineamento Transbrasiliano, bem como pelo estreitamento das faixas aflorantes das formações siluro-devonianas, em comparação ao observado mais ao norte, na borda leste. Um enxame de fotolineamentos NE, interpretados a partir de imagens de sensores remotos, ocorrem tanto ao longo do limite da bacia com o embasamento cristalino, como nas unidades sedimentares eopaleozoicas. Com o suporte de dados de campo, três padrões estruturais foram reconhecidos e correlacionados a eventos deformacionais distintos. A Deformação $\mathrm{D}_{\mathrm{n}}$, de idade ediacarana-cambriana, é reconhecida apenas no embasamento cristalino pré-cambriano, sendo relacionada a uma etapa tardia, retrometamórfica e de caráter plástico-frágil das zonas miloníticas brasilianas. A assinatura desse evento inclui zonas de cisalhamentos transcorrentes destrais orientadas NE-SW e veios de quartzo preenchendo juntas de distensão E-W. A Deformação $\mathrm{D}_{\mathrm{n}+1}$ corresponde a uma nova etapa de movimentação transcorrente destral nas estruturas NE-SW, acompanhada por falhas normais e juntas de distensão com orientação WNW a E-W, neste caso também afetando as unidades siluro-devonianas. A Deformação $\mathrm{D}_{\mathrm{n}+2}$ é caracterizada por falhas normais, diques básicos (correlacionados à Suíte Sardinha, eocretácea), veios silicosos e cristas de arenitos silicificados, todos com orientação NE-SW. Essa última fase resulta de uma distensão com orientação NW-SE, análoga àquela reconhecida mais ao leste, nas Bacias Interiores do Nordeste do Brasil, associada ao rifteamento do Atlântico Sul.
\end{abstract}

Palavras-chave: Bacia do Parnaíba; Borda Sudeste; Análise estrutural.

\begin{abstract}
Along the frontier between Piauí, Bahia and Pernambuco States (Northeast Brazil), the southeastern border of the Parnaíba Basin (BPar) is been mapped as a nonconformity between the Serra Grande Group (GSG) and the Precambrian basement. However, this border is characterized by an expressive NE trend parallel to the one of the Transbrasiliano Lineament, as well as a narrowing of the outcropping belt of the Silurian-devonian formations, as compared to the situation further north, in the east basin border. A swarm of NE-trending photolineaments was interpreted from remote sensing images. They occur very close (or coinciding) to the basin/basement limit or superimposed on the paleozoic units (especially the GSG and the Pimenteiras Formation). Supported by field data, three structural patterns were recognized and correlated to distinct deformation events. $\mathrm{D}_{\mathrm{n}}$ deformation, of ediacaran-cambrian age and observed just in the Precambrian basement rocks, is related to a retrometamorphic, plastic-brittle late stage of Brasiliano mylonite zones. It is characterized by NE-trending dextral transcurrent shear zones, as well as quartz veins filling E-W extension joints. $\mathrm{D}_{\mathrm{n}+1}$ Deformation corresponds to a new stage of transcurrent dextral movement along the NE-trending structures, accompanied by normal faults and extension joints oriented WNW to E-W, in this case overprinting the Silurian-Devonian formations. $\mathrm{D}_{\mathrm{n}+2}$ Deformation is characterized by normal faults, basic dykes (correlated to the Eocretaceous Sardinha Suite), siliceous veins and ridges of silicified sandstones, all of them along the NE-SW trend. This last phase results from a NW-SE extension, analogous to the one recognized further east in the Interior Basins of Northeast Brazil, associated to the South Atlantic rifting.
\end{abstract}

Keywords: Parnaíba Basin; Southeastern border; Structural analysis. 


\section{INTRODUÇÃO}

A Bacia do Parnaíba (BPar) possui um importante acervo de estudos estratigráficos, mas são comparativamente restritas as contribuições para o seu arcabouço e sua evolução estrutural fanerozoica, sendo conferida ênfase ao Lineamento Transbrasiliano (LTB) e às suas reativações (p.ex., Góes et al., 1990; Destro et al., 1994; Cordani et al., 2009, 2013; Spisila, 2011; Chamani, 2011, 2015; Castro et al., 2014, 2016; Daly et al., 2014; Cacama et al., 2015; Fuck et al., 2013). O limite sudeste dessa bacia, na região fronteiriça entre os Estados do Piauí, da Bahia e de Pernambuco (Figura 1), é normalmente cartografado como uma discordância entre os depósitos silurianos do Grupo Serra Grande (GSG) e o embasamento cristalino (Angelim et al., 2004; Vasconcelos et al., 2004; Kosin et al., 2004). No entanto, algumas feições cartográficas e geomorfológicas chamam a atenção para um possível controle tectônico dessa borda da bacia.

A borda sudeste da BPar é caracterizada por uma expressiva orientação NE, paralela ao LTB, bem como pelo estreitamento da faixa aflorante dos litotipos do GSG (Siluriano) e da Formação Pimenteiras (Devoniano) (Figura 1). Em alguns trechos, especialmente entre os municípios de São João do Piauí/PI e Alegrete do Piauí/PI, chama a atenção a ausência da escarpa que caracteriza o contato basal do GSG; por outro lado, essa escarpa é bem desenvolvida no setor sul da área de estudo (entre Curimatá/PI e São João do Piauí) (Figura 2).

Na literatura, é comum a referência a reativações fanerozoicas do LTB condicionando as etapas de evolução da bacia, todavia sem detalhar a expressão dessas reativações. Este trabalho teve o objetivo de caracterizar, a partir da interpretação de imagens de sensores remotos e de dados estruturais de campo, o estilo estrutural e cinemático, bem como a cronologia dessas reativações, correlacionando-as aos intervalos de idade definidos para as unidades estratigráficas que afloram na borda sudeste da BPar. A área abordada está indicada na Figura 2.

\section{CONTEXTUALIZAÇÃO GEOLÓGICA REGIONAL}

A BPar, com as Bacias do Paraná, Solimões e Amazonas, é parte do grupo de grandes sinéclises paleozoicas brasileiras. A BPar foi desenvolvida sobre um embasamento pré-cambriano, em sua maior parte afetado pelo evento Brasiliano, durante o que Almeida e Carneiro (2004) e Zalán (2004) chamaram de "Estádio de Estabilização da Plataforma Sul-Americana".

Devido à dificuldade em entender o complexo arcabouço tectono-sedimentar no contexto de uma bacia única, Góes (1995) cunhou o termo Província do Meio-Norte (também referida como Província Parnaíba, seguindo a definição de Almeida et al., 1981) e a compartimentou em quatro sub-bacias (Parnaíba, Alpercatas, Grajaú e Espigão Mestre) de gênese, idade, estilo tectônico e preenchimento sedimentar distintos. Neste trabalho, foi adotada a designação e definição de Vaz et al. (2007), Zalán (2004) e Milani e Thomaz Filho (2000), corrente na literatura e abaixo sintetizada.

A BPar compreende um estágio de sinéclise que se desenvolveu ao longo do Paleozoico, alcançando o Eotriássico. Ele inclui três sequências de primeira ordem, representando ciclos transgressivos-regressivos completos: Sequências Siluriana-Eodevoniana, Mesodevoniana-Eocarbonífera e Neocarbonífera-Eotriássica. As camadas apresentam grande continuidade lateral e espessuras regulares, características do estilo de subsidência sag.

Mais ao norte, a Bacia das Alpercatas corresponde à Sequência Jurássica, formada por rochas sedimentares e magmáticas (Suíte Mosquito), essas últimas com maior importância na porção centro-oeste da bacia, sendo associadas à abertura do Atlântico Central.

A Bacia de Grajaú corresponde a uma sequência sedimentar de idade cretácea (Aptiano ao Cenomaniano). Essas rochas sedimentares capeiam rochas básicas intrusivas de idade barremiana, a Suíte Sardinha, relacionada ao rifteamento no Atlântico Sul.

A Bacia do Espigão Mestre equivale à porção norte da Bacia Sanfranciscana (corresponde aos grupos Areado e Urucuia na Figura 1), distinguindo-se dessa última por apresentar geometria e arquitetura tectônica distintas (Góes, 1995; Pedreira et al., 2003).

O conhecimento estrutural do LTB na BPar tem sido abordado a partir de interpretações de imagens orbitais, bem como de dados geofísicos e de campo (Góes et al., 1990; Nunes, 1993; Destro et al., 1994; Oliveira e Mohriak, 2003; Cordani et al., 2009; Chamani, 2011, 2015; Santos et al., 2013; Morais Neto et al., 2013; Castro et al., 2014, 2016; Daly et al., 2014; Pedrosa Jr. et al., 2014; Cacama et al., 2015; Lima, 2015; Antunes et al., 2015, 2016). As poucas seções geológicas publicadas (Milani e Thomaz Filho, 2000) ilustram a geometria característica de uma sinéclise, com as sequências paleozoicas sendo afetadas por falhas que, pelo menos em parte, estão associadas ao LTB. No embasamento, esse lineamento corresponde a uma zona de cisalhamento plástica com direção NE-SW relacionada à orogênese Brasiliana. Uma etapa de movimentação tardia, em baixa temperatura, ocorreu no Ediacarano-Cambriano (idade baseada na fauna identificada por Barroso et al., 2014, no Graben de Jaibaras, NW do Ceará), controlou a estruturação de grabens no substrato da bacia (Cacama et al., 2015), também caracterizados em linhas sísmicas na porção central da bacia (Oliveira e Mohriak, 2003; Morais Neto et al., 2013; Antunes et al., 2015, 2016). Por outro lado, a expressão 


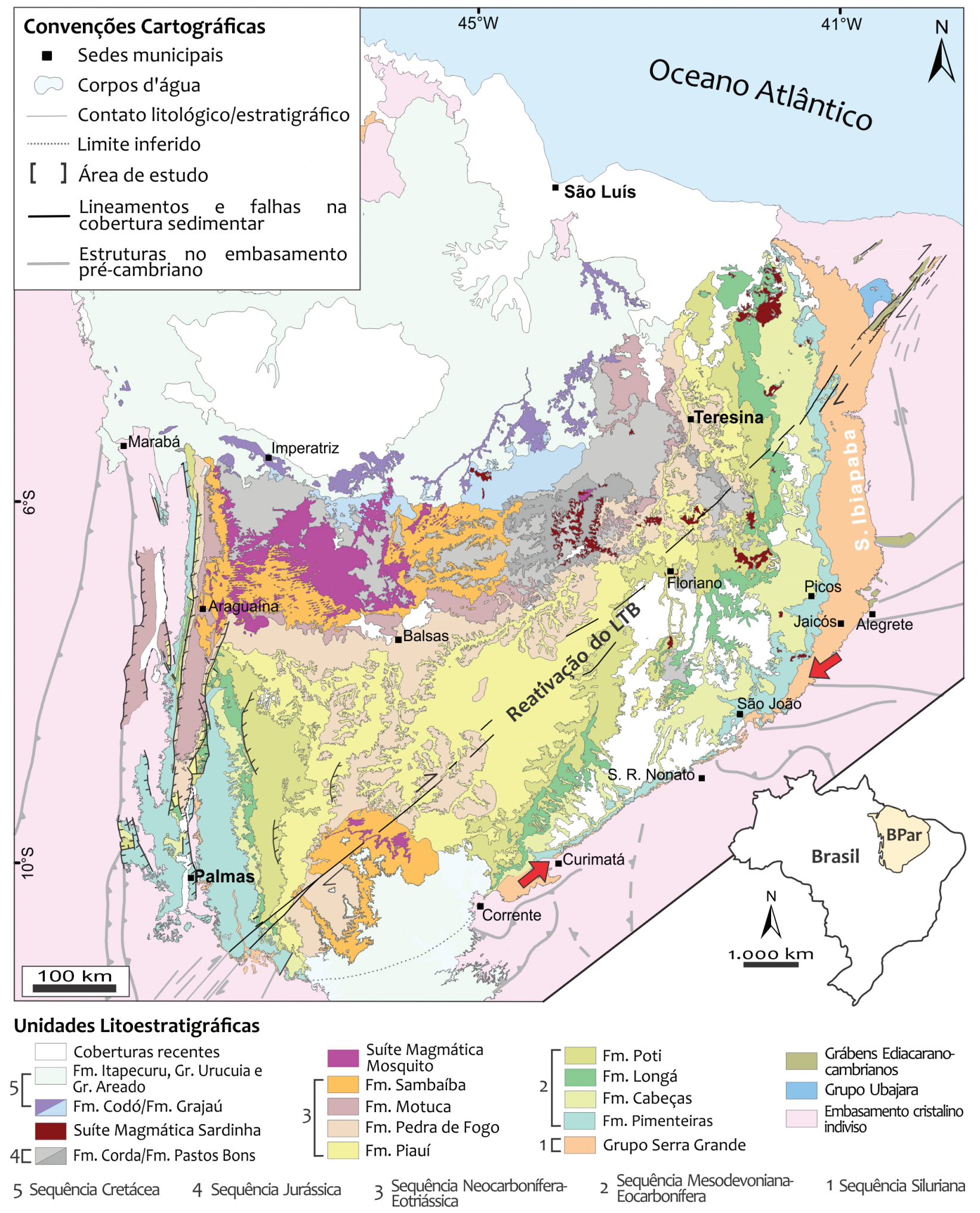

LTB: Lineamento Transbrasiliano; BPar: Bacia do Parnaíba.

Figura 1. Mapa geológico da Bacia do Parnaíba (compilado, com algumas modificações, de Schobbenhaus, 2004, englobando contribuições do Projeto Bacia do Parnaíba - Chevron/UFRN/PPGG), mostrando o estreitamento da faixa aflorante do Grupo Serra Grande e da Formação Pimenteiras, indicado pelas setas vermelhas. Observar o paralelismo entre o Lineamento Transbrasiliano e a borda sudeste da Bacia do Parnaíba. 
do LTB afetando as unidades pós-ordovicianas a eotriássicas, no interior da bacia, corresponde a falhas, juntas e bandas de deformação, sendo que Chamani $(2011,2015)$ detalhou a ocorrência de sismitos em várias unidades da $\mathrm{BPar}$, interpretados como indícios de atividade tectônica ao longo do LTB e outras estruturas. Essas estruturas teriam se originado em resposta à impressão de novos campos de tensões, ainda no contexto paleotectônico do Gondwana ou relacionados à formação das margens continentais leste e equatorial sul-americanas.

\section{MATERIAIS E MÉTODOS}

O desenvolvimento deste trabalho se deu por meio das seguintes etapas:

- análise prévia de mapas geológicos da bacia e suas adjacências (especialmente os mapas em escalas de 1:1.000.000, 1:250.000 e 1:100.000, disponibilizados no banco de dados da Companhia de Pesquisa de Recursos Minerais - CPRM) e uso do software Google Earth Pro para a seleção de afloramentos e perfis geológicos;

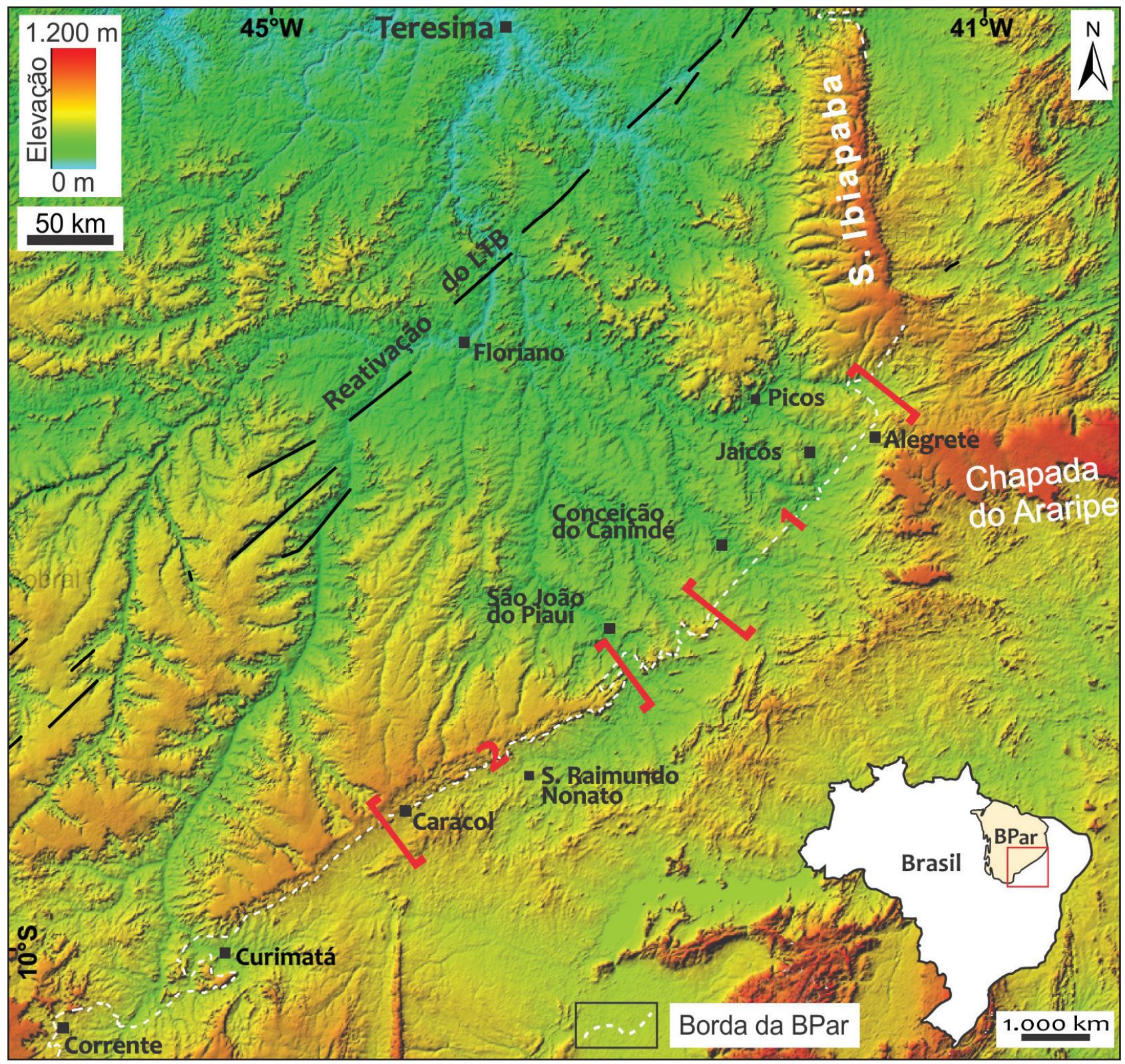

BPar: Bacia do Parnaíba.

Figura 2. Modelo digital do terreno da porção sudeste da Bacia do Parnaíba, localizando os setores norte (1) e sul (2) da área de estudo. 
- análise de fotolineamentos por meio de imagens de relevo sombreado geradas a partir de produtos de sensores remotos ativos SRTM (Shuttle Radar Topographic Mission), assim como dos sensores passivos Landsat TM 5, ETM+ 7 e OLI 8;

- coleta de dados estruturais, principalmente ao longo do contato entre o embasamento e a cobertura sedimentar paleozoica na borda da bacia;

- comparação e ajustes das análises baseadas em imagens orbitais, especialmente nas imagens de relevo sombreado, com base nas informações adquiridas em campo e dos mapas obtidos no banco de dados da CPRM.

Com base nas diferenças geomorfológicas, foram selecionadas duas áreas para extração de fotolineamentos nas imagens de sensores remotos orbitais (Figura 2). A subárea norte situa-se na região sem escarpa da borda da bacia, entre os municípios de Conceição do Canindé/PI e Alegrete do Piauí, enquanto a subárea sul, com escarpas, estende-se de Caracol/PI a São João do Piauí (Figura 2).

\section{Análise de macroestruturas em produtos de sensores remotos}

Imagens de relevo sombreado com diferentes filtros direcionais têm sido largamente utilizadas para identificar falhas e lineamentos, com o auxílio de dados geológicos (Onorati et al., 1992; Oguchi et al., 2003; Ganas et al., 2005; Abarca, 2006). Neste trabalho, a cartografia de lineamentos utilizou imagens SRTM com resolução espacial de $30 \mathrm{~m}$, disponibilizadas pela United States Geological Survey (USGS). As imagens SRTM foram iluminadas artificialmente com inclinação de $45^{\circ}$ nas direções azimutais $315^{\circ}, 0^{\circ}, 45^{\circ}$ e $90^{\circ}$, para fornecer um relevo sombreado em alto ângulo com a orientação da iluminação aplicada.

Vale destacar que, embora bastante eficazes em mapeamentos geológicos de áreas com grandes dimensões, a extração de lineamentos estruturais a partir de imagens de radar exige certo rigor técnico, a fim de evitar a geração de informação espúria, derivada de uma interpretação equivocada da estrutura/alvo analisado ou sem qualquer significado geológico (Gilluly, 1976; O’Leary, 1976; Kellndorfer et al., 2004). Dessa forma, os fotolineamentos mais visíveis e com dimensões apreciáveis foram identificados e mapeados utilizando o software ArcMap 10.1. No mapeamento desses fotolineamentos, a escala das imagens de relevo sombreado foi fixada em 1:1.000.000, compatível com a cartografia da CPRM. No entanto, sempre que necessário, a escala foi ampliada para melhor caracterização de fotolineamentos já identificados em outras fontes, como os mapas geológicos da CPRM. Para não sobrecarregar os mapas assim obtidos, foi evitada a cartografia sistemática de drenagens orientadas com pequenas dimensões, com significado mais incerto.
Para reduzir os erros associados à interpretação desses produtos de sensores remotos, as imagens de relevo sombreado foram comparadas a produtos de sensores passivos, como o Landsat, ou a imagens de alta resolução obtidas no software Google Earth, permitindo, inclusive, mapear enxames de diques básicos ao longo da borda da bacia e identificar cristas de arenitos silicificados, ressaltadas no relevo. Para mapear os diques básicos nas imagens Landsat, foram utilizadas composições em falsa-cor (geradas no ENVI 5.0) em duas cenas (ponto/órbita: 218/065 e 218/066) capturadas pelo sensor OLI no dia 24 de março de 2015.

A construção de diagramas de roseta foi realizada no software RockWorks 16 e baseou-se no método de contagem de direção versus comprimento dos fotolineamentos.

Neste trabalho, adotou-se a terminologia utilizada por Jardim de Sá et al. (1993), que distingue os termos fotolineamento (traço usualmente retilíneo e discreto, característico de estrutura descontínua, frágil a dúctil-frágil) e fotolineação (traços contínuos e penetrativos, definindo padrões retilíneos ou curvilíneos, característicos de estruturas dúcteis, tais como foliações, lineações e zonas de cisalhamento plásticas). Tendo em vista o objetivo deste trabalho, com ênfase na deformação frágil ou dúctil-frágil, as imagens ilustram exemplos de fotolineamentos e os padrões de fotolineações são apenas descritos, de modo a não sobrecarregar as ilustrações.

Finalmente, levando em conta o padrão estrutural (trends estruturais em alto ou baixo ângulo com a borda da bacia) e geomorfológico (ausência ou presença de escarpas), bem como a adequação das ilustrações a este texto, a área de estudo foi dividida em duas subáreas, quase contíguas (Figura 2).

\section{Análise de mesoestruturas}

$\mathrm{Na}$ escala de afloramento, as estruturas foram caracterizadas de acordo com a sua geometria, o seu estilo e os seus indicadores cinemáticos. Esses atributos foram utilizados para agrupar (ou diferenciar) estruturas em relação a um dado regime cinemático. Assim organizados, os dados de campo foram então plotados em projeções equiárea no software Faultkin (projeção Schmidt-Lambert, hemisfério inferior), facilitando a sua correlação com macroestruturas (em geral, fotolineamentos e basculamento de camadas).

As estruturas caracterizadas foram comparadas entre si com base em modelos de cisalhamento e no sistema de fraturas de Riedel, considerando etapas de reativações de estruturas análogas ao LTB, ou seja, com orientação NE-SW, presentes no substrato da bacia e/ou no embasamento cristalino contíguo. As interpretações foram esboçadas como modelos esquemáticos representando em planta (mapa) a orientação e a cinemática das estruturas e dos eventos deformacionais, estimando a orientação dos eixos de strain (e paleotensões assumindo regimes de cisalhamento puro) que produziram esses conjuntos de estruturas. 
Por fim, a cronologia das estruturas foi estabelecida com base nas unidades sedimentares afetadas, na correlação com rochas básicas e em eventos geodinâmicos reconhecidos no entorno da BPar, seguindo proposta de Jardim de Sá et al. (2015).

\section{SÍNTESE DA GEOLOGIA NA BORDA SUDESTE DA BACIA DO PARNAÍBA}

$\mathrm{Na}$ área de estudo, o embasamento cristalino é capeado pelas rochas sedimentares do GSG (Formações Ipu, Tianguá e Jaicós) e do Grupo Canindé (somente as Formações Itaim, Pimenteiras e Cabeças ocorrem na região estudada), sendo que os arenitos do GSG e da Formação Cabeças sustentam as linhas de cuesta na borda da bacia (Figura 1). As rochas subvulcânicas básicas de idade eocretácea, da Suíte Sardinha, intrudem essas unidades na forma de diques, soleiras e outros tipos de corpos, especialmente nas proximidades do município de Isaías Coelho, no Piauí. Remanescentes de grabens ediacaranos-cambrianos (análogos aos grabens de Jaibaras e Cococi) ocorrem localmente, encaixados no embasamento, e também são capeados pelo GSG, tais como os grabens de São Julião (Parente et al., 2004) e de Araçá (Freitas, 2014; Lima, 2016), já fora das áreas escolhidas para detalhamento.

\section{LINEAMENTOS E MACROESTRUTURAS}

De forma geral, a borda da bacia na região estudada apresenta-se bastante afetada por estruturas frágeis, embora possua um extenso capeamento de depósitos coluvionares na base das encostas das escarpas, dificultando a obtenção de informações precisas quanto à natureza e à localização do contato basal do GSG (salvo algumas exposições, naturais ou artificiais, com exemplos ilustrados adiante).

As Figuras 3 e 4 ilustram a disposição geral, a frequência e as dimensões desses fotolineamentos que, preliminarmente, foram subdivididos em fotolineamentos do embasamento (em vermelho) e da cobertura sedimentar (em amarelo), com base na borda da bacia definida nas cartas da CPRM.

Nos terrenos cristalinos, foram identificados fotolineamentos superpostos, paralelos ou truncando as fotolineações associadas à trama da deformação dúctil brasiliana. O caráter retilíneo e discreto desses lineamentos permite inferir prováveis reativações de caráter dúctil-frágil a frágil nas estruturas do embasamento. Foram encontradas duas famílias de fotolineamentos, uma com orientação NE-SW e outra que varia de WNW-ESE a ENE-WSW. Essas estruturas aparecem com frequência ao longo da área de exposição do embasamento no setor norte da área de estudo, sendo menos frequentes e menores no setor sul, onde ficam encobertas por sedimentos neógenos. Os fotolineamentos NE-SW são mais expressivos, podendo atingir individualmente mais de $15 \mathrm{~km}$ de comprimento (Figuras 3 e 4).

Na cobertura sedimentar paleozoica da BPar, foram identificadas três famílias de fotolineamentos, com orientações NE-SW, E-W e NW-SE (Figuras 3 e 4; nesta última observa-se uma pétala subordinada identificando estruturas N-S). Os fotolineamentos NE-SW são mais frequentes, variam de 1 a $12 \mathrm{~km}$ de comprimento e configuram-se, desde já, como uma importante evidência de controle estrutural nessa borda da bacia. Os fotolineamentos com orientações WNW-ESE e NW-SE ocorrem de forma subordinada, ainda que com frequência apreciável, muitas vezes recortando a interface entre o embasamento cristalino e as rochas sedimentares da bacia.

Também foram observados, especialmente na cobertura sedimentar neógena, fotolineamentos com direção aproximada N-S. Por não se evidenciarem nos dados de campo, esses fotolineamentos não foram alvo de detalhamento neste trabalho. Todavia, deve ser mencionada a sua importância nas bordas oeste e sudoeste da bacia, onde correspondem a falhas normais ou normais oblíquas, porém de idade neopaleozoica-eotriássica (Souza, 2016; Santos et al., 2016).

\section{RELAÇÕES ENTRE MACRO E MESOESTRUTURAS}

Com base nas informações obtidas em campo, na bibliografia especializada e de ferramentas como o Google Earth, é possível discutir em maior detalhe as reativações dos fotolineamentos mapeados na BPar e no embasamento da Província Borborema, na presente região de estudo.

Nas imagens de relevo sombreado apresentadas nas Figuras 3, 4 e 5, é possível identificar os traços de algumas zonas de cisalhamento brasilianas importantes, tais como a extremidade aflorante do Lineamento Pernambuco (LPE; ao sul da Bacia do Araripe), com orientação E-W, e um ramo do Lineamento Patos (LPA; a NW da Bacia do Araripe), com orientação NE-SW. Os fotolineamentos são consistentes com arranjos $\mathrm{S}-\mathrm{C}$ destrais que alcançam a borda da bacia e certamente continuam no seu substrato. Ocorre também uma série de fotolineamentos/fotolineações de orientação NE-SW na região entre essas duas grandes estruturas.

Evidências de campo indicam que os fotolineamentos cartografados no embasamento correspondem a reativações de caráter dúctil-frágil a frágil e, portanto, relacionadas a eventos tardios ou posteriores à trama dúctil brasiliana. A Figura 6A ilustra, em visada Google Earth, uma drenagem orientada NE-SW, seguindo o contato basal do GSG, o qual não ocorre (removido por erosão) a SE dessa estrutura.

As fotolineações que correspondem a estruturas E-W do LPA exibem, ao sul de São Julião, uma mudança de ENE para NE no trend (cf. Figuras 3 e 5). Nessa região, a trama do embasamento se torna paralela à borda da bacia e deve 
ter continuidade no seu substrato. É plausível que as anisotropias do embasamento relacionadas a essa trama NE-SW tenham sido reativadas por campos de tensões mais jovens, que afetam os depósitos paleozoicos da bacia. Por outro lado, a trama E-W do LPE adentra no substrato da BPar, ao sul de Conceição do Canindé (Figuras 3 e 5).

A combinação de imagens Google Earth e composições falsa-cor Landsat 8 OLI permitiu caracterizar um enxame de diques (além de soleiras) básicos da Suíte Sardinha, intrusivos na cobertura sedimentar paleozoica, com orientação NE paralela à borda da bacia (Figuras 6B, 7A e 7C). Também ocorrem enxames de veios silicosos de baixa temperatura cortando os sedimentos siluro-devonianos do GSG. Em campo, esses veios possuem a mesma orientação NE-SW, mergulhos fortes e, por vezes, subparalelos aos contatos dos diques (Figura 6C). Também podem ocorrer aproveitando-se de anisotropias das rochas, percolando ao longo de camadas e/ou planos de falhas (ilustrações na Figura 7C).Esses veios podem ser creditados a efeito termal/de contato - por exemplo em bordas de diques e soleiras (Sachs et al., 2015) — ou deposição de sílica hidrotermal (lixiviados dos arenitos encaixantes) no contato e nas adjacências. A ausência de topografia e a baixa resolução das imagens SRTM fazem com que alguns desses diques, de menores dimensões, não estejam realçados nas imagens de relevo sombreado; no entanto, eles foram representados em mapa e perfil da Figura 7.

Outra feição associada são as expressivas cristas de arenitos do GSG, alinhadas na direção NE, a sudoeste do município de Patos do Piauí (PI). Essas cristas correspondem a arenitos silicificados, com diques básicos adjacentes (Figura 6D).

Os fotolineamentos NE-SW que afetam as rochas da bacia podem estar relacionados a eventos distintos na evolução tectônica da bacia, que produziram ou reativaram estruturas com essa orientação, mas com cinemática distinta. Desse modo, essas reativações (ou nucleação de novas falhas) podem desenvolver/exibir slickenlines de rake alto (refletindo falhas normais) ou de rake baixo (refletindo falhas transcorrentes), somente discriminadas a partir

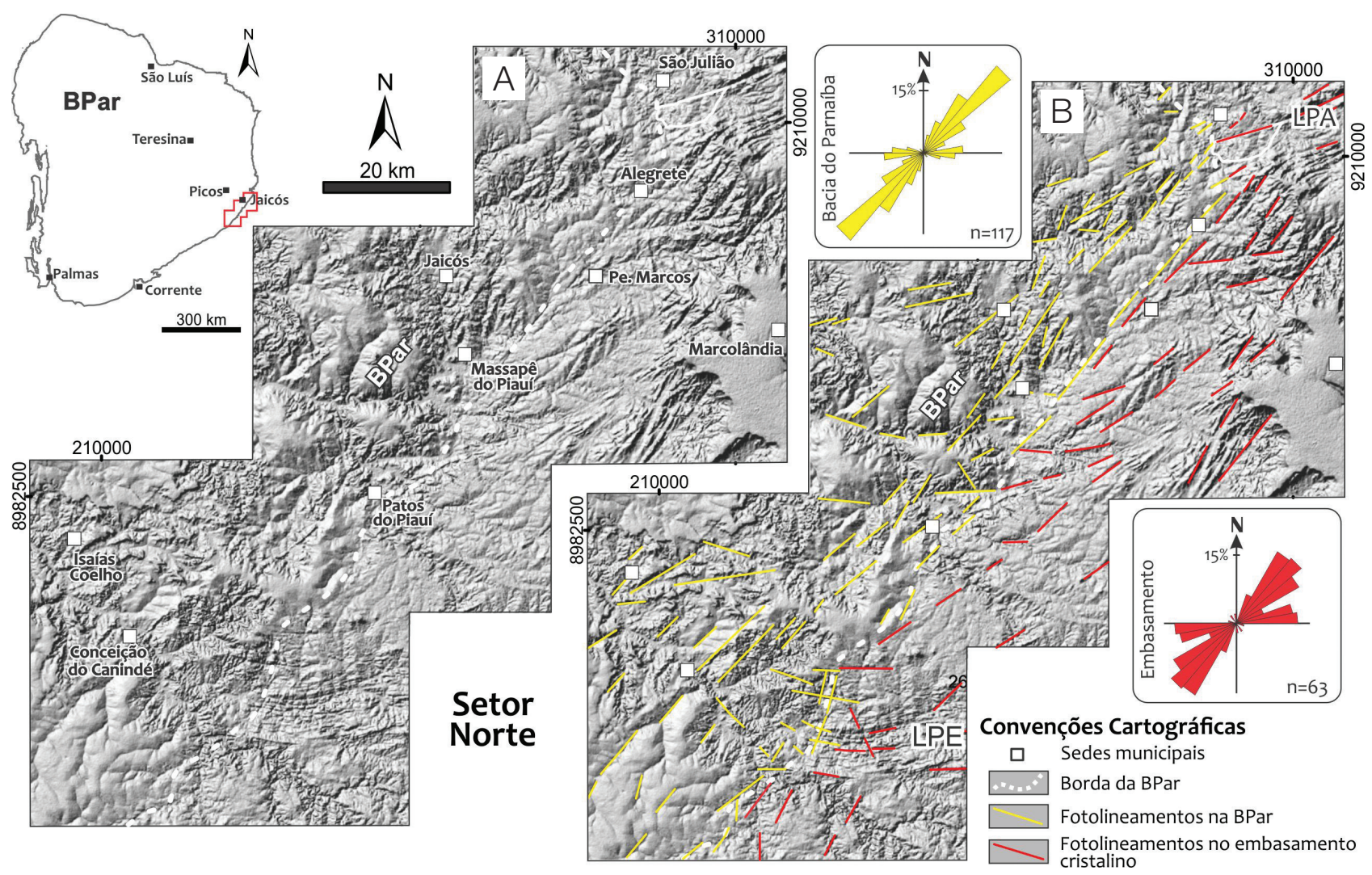

LPE: Lineamento Pernambuco; LPA: Lineamento Patos; BPar: Bacia do Parnaíba.

Figura 3. Imagens de relevo sombreado em escala de 1:1.000.000 com iluminação proveniente de NW, no setor norte da área de estudo. Em (A), imagem não interpretada; em (B), fotolineamentos interpretados. Os traçados foram preliminarmente classificados como fotolineamentos do embasamento cristalino (em vermelho) e da cobertura paleozoica (em amarelo), com base nas anisotropias características do embasamento (fotolineações) e na linha de borda da bacia, definida pela Companhia de Pesquisa de Recursos Minerais. As rosetas explicitam a orientação preferencial NE-SW dessas estruturas. Fotolineamentos com orientação ENE-WSW e E-W ocorrem de forma subordinada. 
dos dados obtidos em campo. A interpretação de imagens de sensores remotos comumente não permite discriminar esse atributo cinemático de um dado lineamento (salvo pela orientação sistemática de estruturas em padrão escalonado, característico de transcorrências). No mapeamento apresentado nas Figuras 7A e 7B, optou-se por representar o símbolo de falhas apenas quando houvessem dados de campo nas proximidades do lineamento cartografado.

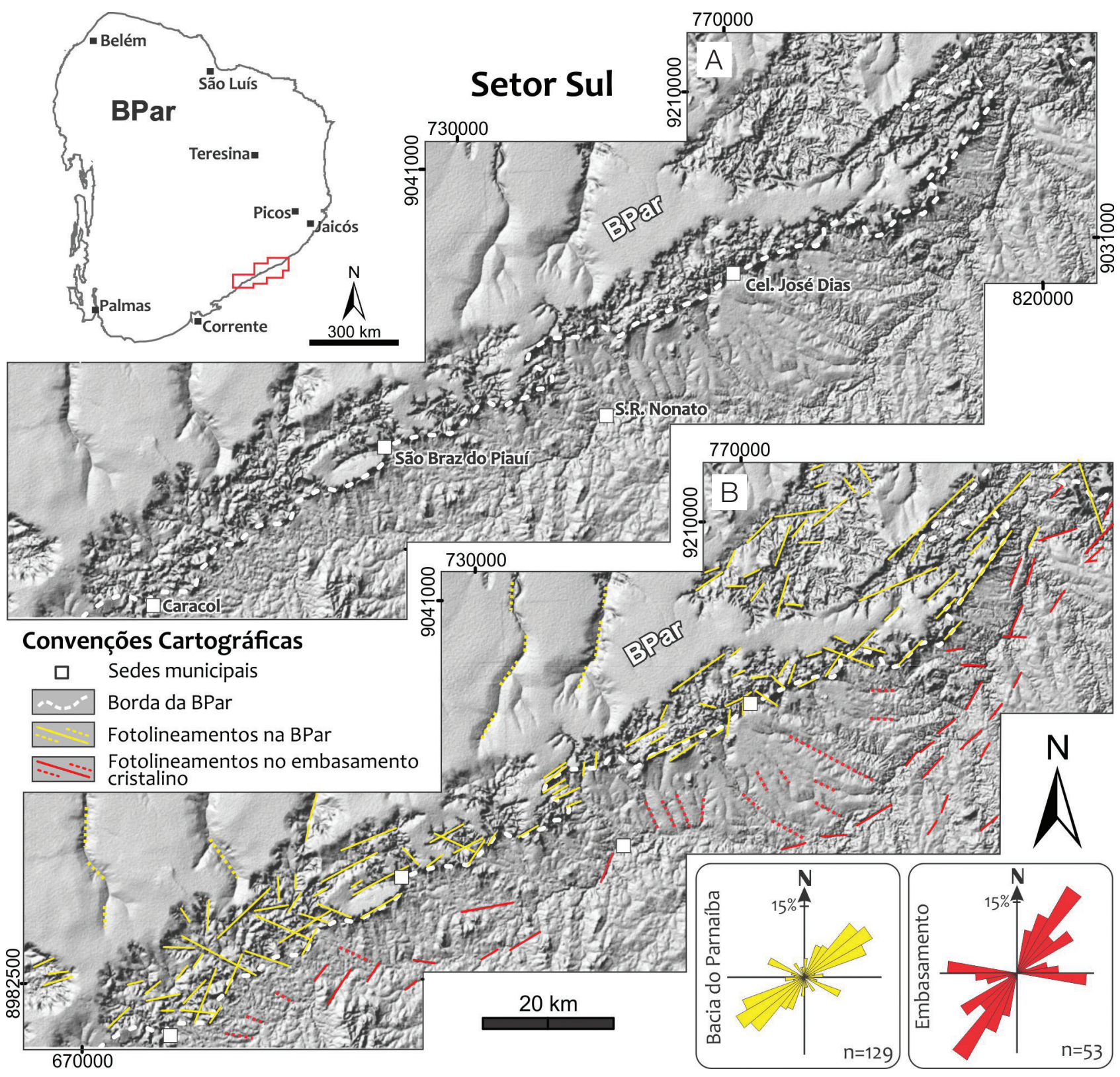

BPar: Bacia do Parnaíba.

Figura 4. Imagens de relevo sombreado em escala de 1:1.000.000 com iluminação proveniente de NW no setor sul da área de estudo. Em (A), imagem não interpretada; em (B), fotolineamentos interpretados. Os traçados foram preliminarmente classificados como fotolineamentos do embasamento cristalino (em vermelho) e da cobertura paleozoica (em amarelo), principalmente com base na linha de borda da bacia definida pela Companhia de Pesquisa de Recursos Minerais . As rosetas explicitam a orientação preferencial NE-SW dessas estruturas. Fotolineamentos com orientação NW-SE e E-W ocorrem de forma subordinada. Ao contrário do setor norte (Figura 3), uma extensiva cobertura neógena (aluvionar, eólica, coluvionar na borda das escarpas) dificulta a observação da trama do embasamento cristalino. Nas regiões de expressiva cobertura neógena, os fotolineamentos estão indicados pelas linhas pontilhadas. 


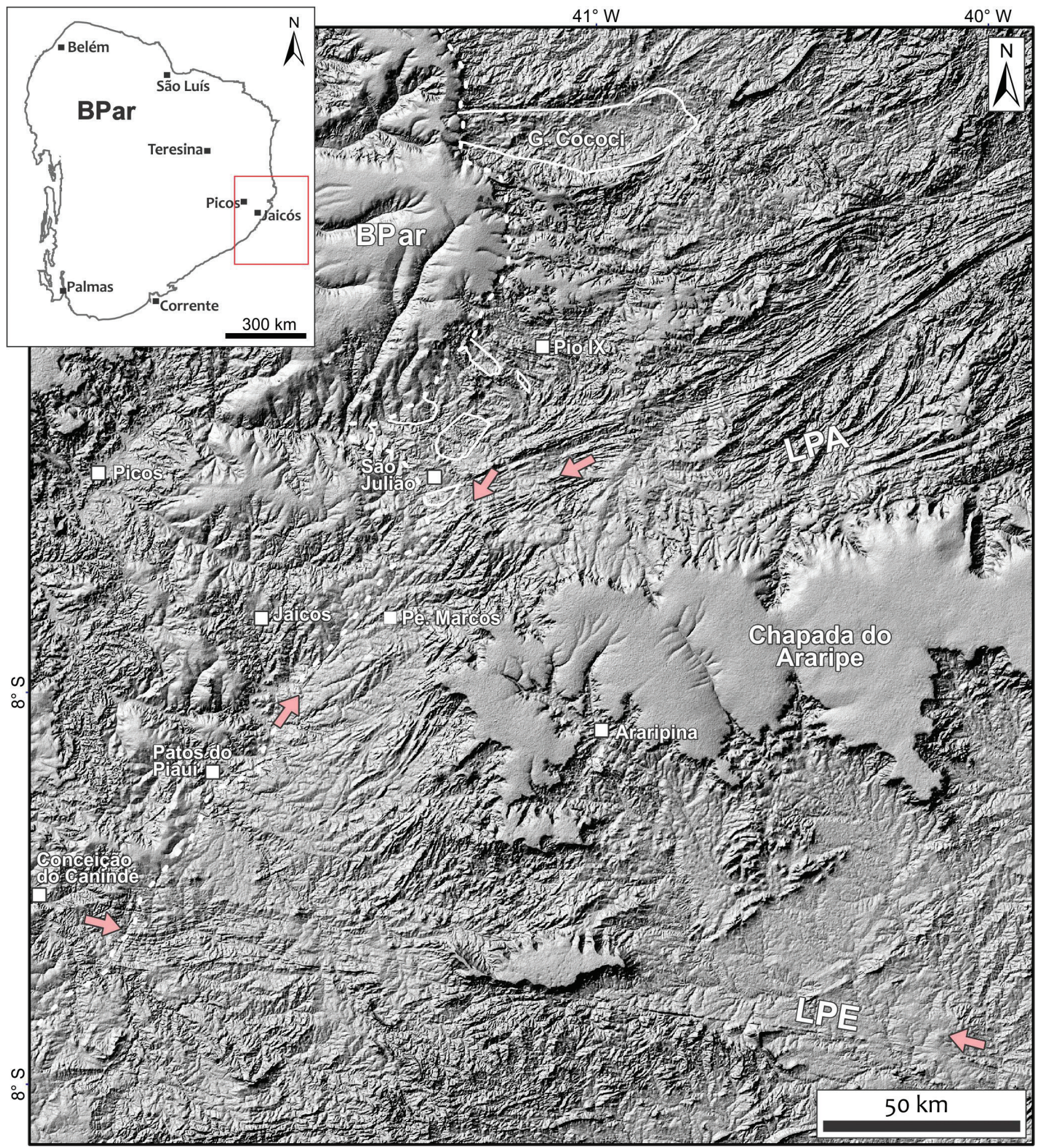

LPE: Lineamento Pernambuco; LPA: Lineamento Patos; BPar: Bacia do Parnaíba.

Figura 5. Imagem de relevo sombreado com iluminação proveniente de NW, realçando as zonas de cisalhamento (deformação plástica) brasilianas no embasamento cristalino, alcançando de forma transversal ou em baixo ângulo a borda SE da Bacia do Parnaíba, como indicado pelas setas rosas. Em branco foi esboçado o contorno de remanescentes de grabens ediacaranos-cambrianos, baseado na cartografia da Companhia de Pesquisa de Recursos Minerais (Angelim et al., 2004; Kosin et al., 2004). 
De forma semelhante ao que acontece no embasamento, os fotolineamentos WNW-ESE da cobertura sedimentar (Figuras 3 e 4) podem refletir uma distensão NNE-SSW associada à transcorrência destral nas falhas NE-SW da bacia. Em afloramentos situados ao norte do município de Coronel José Dias, foram observadas falhas normais que basculam para SSW as camadas da Formação Pimenteiras. Essas estruturas seriam equivalentes a juntas $\mathrm{T}$, do modelo de fraturas de Riedel.
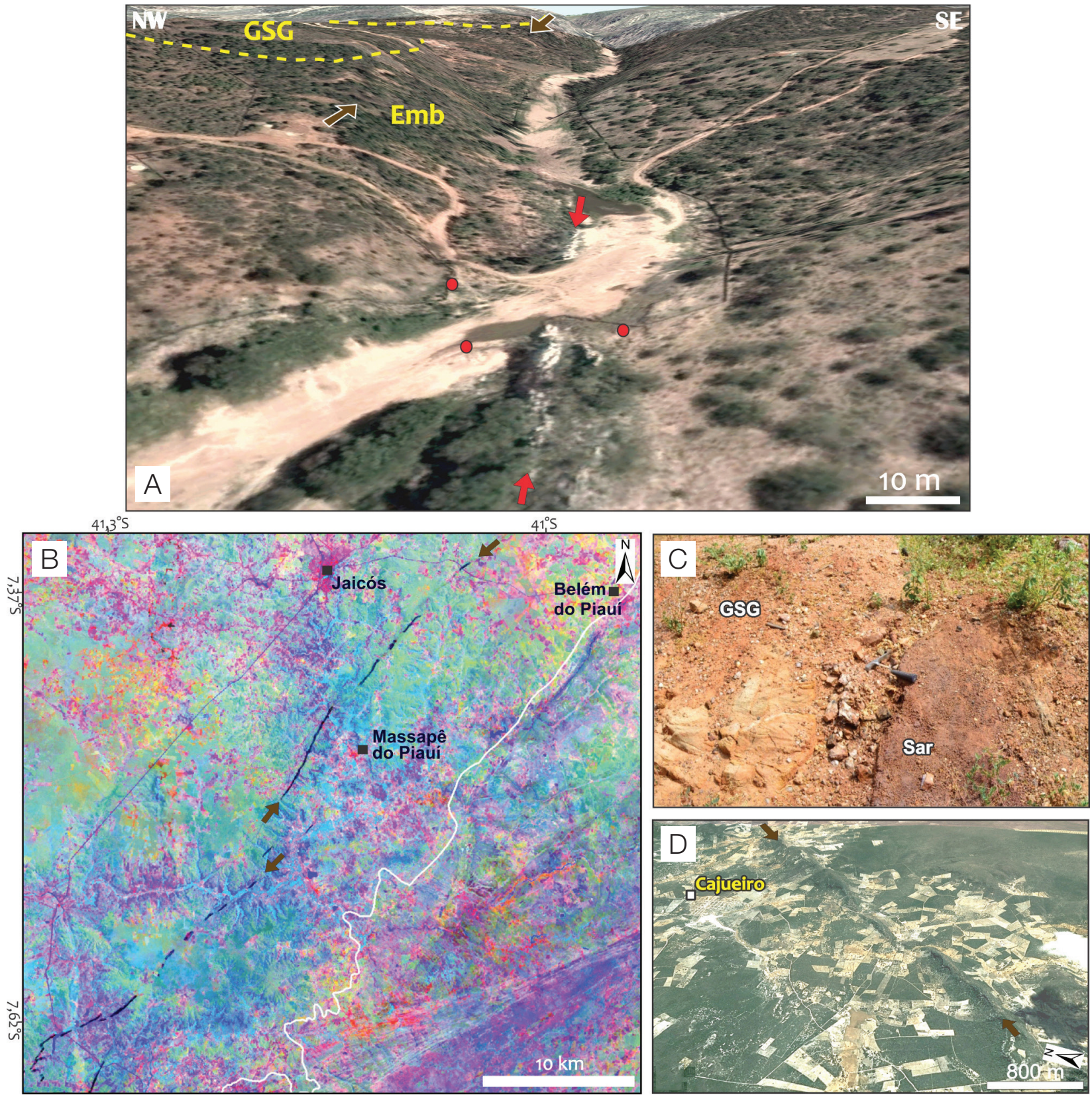

Emb: Embasamento; Sar: Suíte Sardinha; GSG Grupo Serra Grande.

Figura 6. (A) Visada Google Earth destacando uma drenagem orientada NE-SW que acompanha (mas não coincidindo com) o contato basal do Grupo Serra Grande, o qual não ocorre (removido por erosão) a SE dessa estrutura. As setas em vermelho indicam veios de quartzo ao longo de uma zona de cisalhamento destral brasiliana e os círculos vermelhos localizam afloramentos de milonitos nesta zona (ilustrações na Figura 8); (B) Imagem Landsat 8 OLI (composição R[PC1]G[PC6]B[PC2]) ressaltando enxame de diques básicos com direção NE, paralelos à borda da Bacia do Parnaíba (indicada pela linha branca); (C) Contato entre arenito do Grupo Serra Grande e dique de diabásio da Suíte Sardinha, também com direção NE-SW. Observar veio silicoso alojado no contato; (D) Crista de arenito silicificado do Grupo Serra Grande, com orientação NE-SW. 


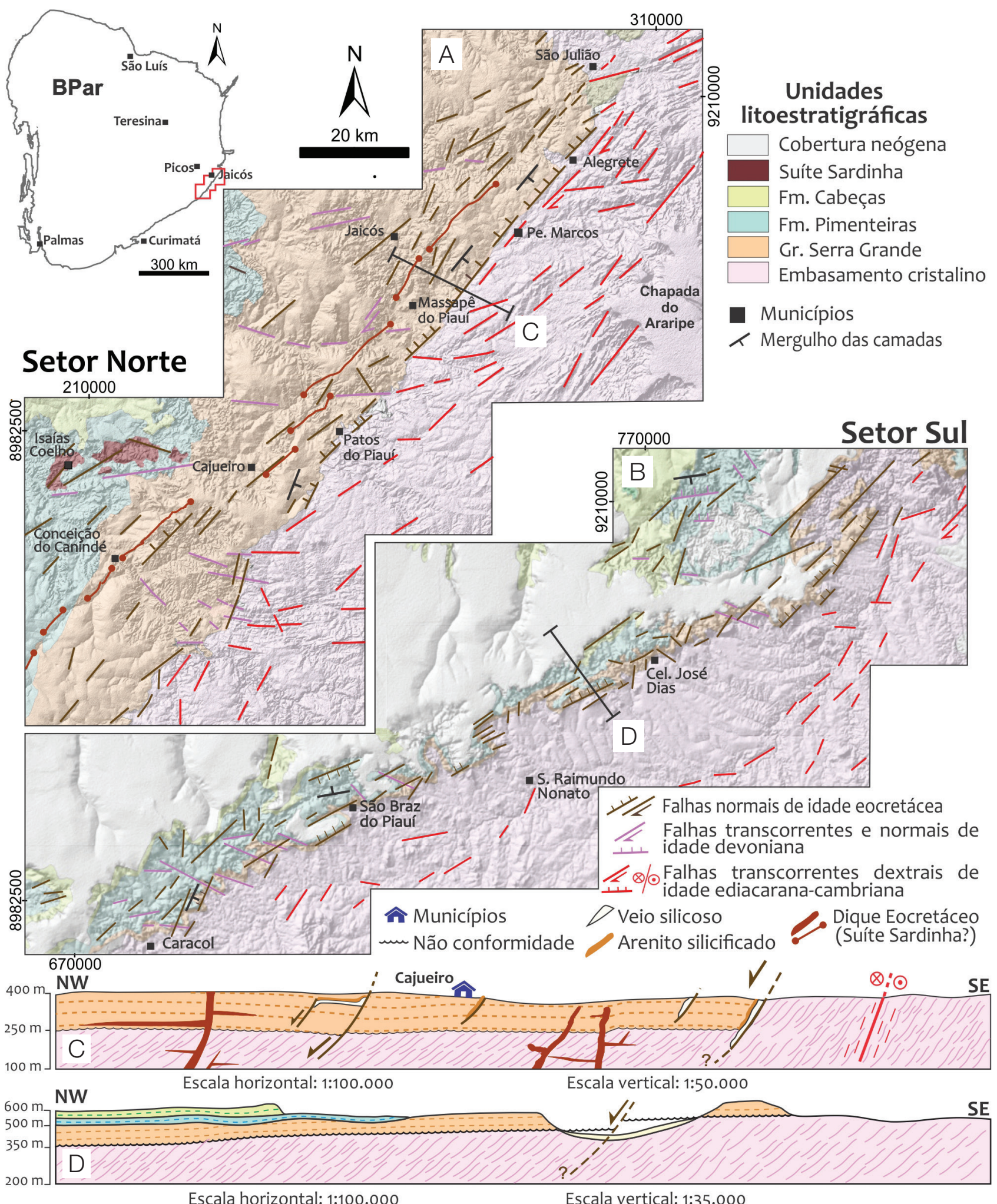

BPar: Bacia do Parnaíba.

Figura 7. Mapas geológicos dos setores norte (A) e sul (B) da área de estudo, ilustrando suas principais estruturas. Os perfis esquemáticos ilustram o contato falhado entre o embasamento e o Grupo Serra Grande (C) e a discordância interceptada por falha, a leste de Coronel José Dias (D). 


\section{EVOLUÇÃO ESTRUTURAL NA BORDA SUDESTE DA BACIA DO PARNAÍBA}

Com base na geometria, na cinemática das estruturas e nos marcadores cronoestratigráficos associados, foram caracterizados, pelo menos, três eventos deformacionais $\left(D_{n}, D_{n+1}\right.$, $\left.\mathrm{D}_{\mathrm{n}+2}\right)$ na região estudada.

\section{Deformação $D_{n}$}

$\mathrm{O}$ evento deformacional $\mathrm{D}_{\mathrm{n}}$ é relacionado à evolução das zonas miloníticas brasilianas no seu estágio tardio e retrometamórfico, sendo constituído por estruturas observadas unicamente no embasamento pré-cambriano a cambriano. Na porção norte da área de estudo, entre Alegrete do Piauí e Patos do Piauí, o embasamento cristalino exibe faixas estreitas (largura de dezena a centena de metros), com caráter descontínuo na escala das imagens, onde gnaisses e rochas miloníticas de mais alta temperatura (e anteriores ao evento $\mathrm{D}_{\mathrm{n}}$ ) são recortadas por zonas de cisalhamento de caráter dúctil-frágil com direção NE-SW (a ENE) (Figuras 3 e 5). Essas zonas de cisalhamento retrometamórficas funcionaram com cinemática destral (Figuras $8 \mathrm{~A} \mathrm{e} 8 \mathrm{~B}$ ), analogamente às estruturas de alta temperatura que as precederam. Planos $\mathrm{C}$ e C' dos milonitos de baixa temperatura truncam a foliação milonítica (S) de alta temperatura, podendo afetar ou alojar veios de quartzo com orientação E-W a ESE-WNW, indicativos da cinemática transcorrente destral nos planos NE-SW (Figuras 8A, 8B e 8C). Falhas sinistrais WNW-ESE podem ocorrer localmente (Figura 8C).
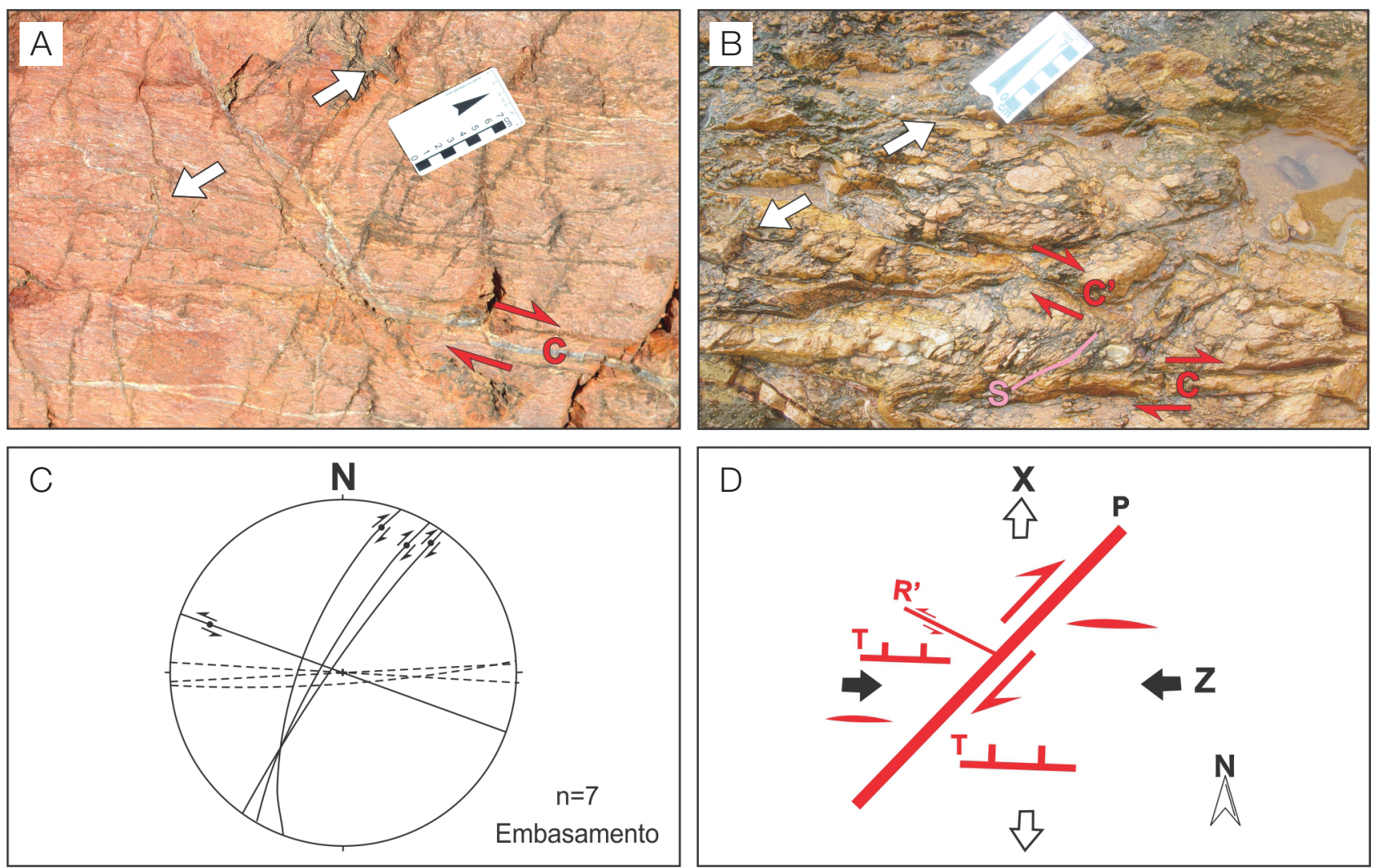

falhas ou planos C -- juntas de distensão

cinemática

tr estimativa dos eixos de strain $(X, Z)$ falha transcorrente dextral $(P) \quad y^{y}$ falhas normais

juntas de distenção (T) falha antitética (R')

Figura 8. (A) Trama ultramilonítica de alta temperatura recortada por veios de quartzo preenchendo espaços dilatacionais em ângulo ou acompanhando a foliação. Movimento destral é inferido a partir do segmento de veio oblíquo em relação à foliação; (B) Retrabalhamento da trama milonítica em granitoide, a qual é recortada por superfícies discretas que correspondem a planos C ou C', de caráter frágil a dúctil-frágil. Relictos de estruturas S-C de mais alta temperatura são também observados (em rosa); (C) Projeção equiárea para falhas e zonas de cisalhamento dúcteis-frágeis relacionadas à Deformação $D_{n}$ em rochas do embasamento da bacia, setor norte da área estudada. Observa-se o arranjo de falhas transcorrentes destrais NE-SW, transcorrência sinistral (antitética) NW-SE e juntas de distensão (T) aproximadamente E-W; (D) modelo interpretativo desse sistema de deformação com estruturas relacionadas ao evento $D_{n}$ ilustradas em planta, e posicionamento estimado dos eixos de strain (eixos X, estiramento; Z, encurtamento). 
Estruturas aflorantes associadas a esse evento deformacional são cronologicamente bem caracterizadas pelo seu registro nos litotipos que preenchem os grabens molássicos do estágio tardio da Orogênese Brasiliana (Parente et al., 2004). Tais grabens ocorrem ao longo da borda leste da BPar, a exemplo de Jaibaras (Cacama et al., 2015), Cococi, São Julião e Araçá, esse último situado ao sul da área de estudo (Lima, 2016). Os dados de campo obtidos nesses últimos trabalhos evidenciam que esses grabens constituem bacias pull-apart associadas a zonas transcorrentes destrais.

$\mathrm{O}$ evento transcorrente destral $\mathrm{D}_{\mathrm{n}}$ e os grabens associados também são reconhecidos no substrato da bacia ao longo do LTB, a NW da área deste estudo. Morais Neto et al. (2013), Lima (2015), Antunes et al. (2016) e Castro et al. (2016) interpretaram em linhas sísmicas e/ou modelaram anomalias gravimétricas associadas a estruturas de grabens pré-silurianos que acompanham o trend do LTB a SW de Floriano (PI).

Nessa área de estudo, a orientação e a cinemática dos planos de falhas (Figura 8C) podem ser integradas em um campo de deformação com eixos de encurtamento $(Z)$ na direção aproximada E-W/ENE e distensão (X) N-S/ NNW (Figura 8D). As estruturas NE-SW incluiriam elementos subparalelos e sintéticos (R, P) aos planos principais, enquanto as transcorrências sinistrais NW-SE representariam estruturas antitéticas do tipo R', em analogia ao modelo de Riedel (Figura 8D). O enxame de zonas de cisalhamento de baixa temperatura, na borda SE da BPar, deve ter correspondência/correlação com as estruturas tardias da Zona de Cisalhamento (Lineamento) Transbrasiliana.

\section{Deformação $D_{n+1}$}

Este evento deformacional também está relacionado a transcorrências destrais NE-SW, embora seja restrito às unidades sedimentares paleozoicas da bacia (Figuras 7, 8 e 9). A separação dessas estruturas em dois eventos distintos é justificada pela não conformidade que separa os arenitos do GSG e o embasamento cristalino.

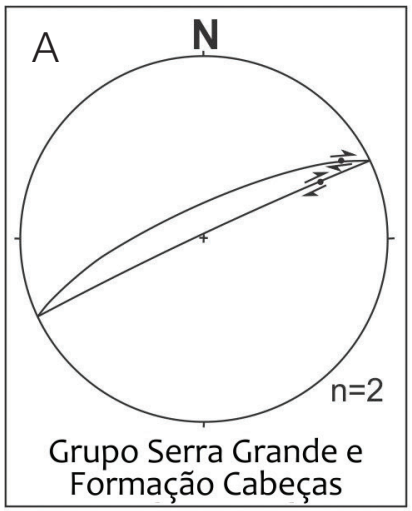

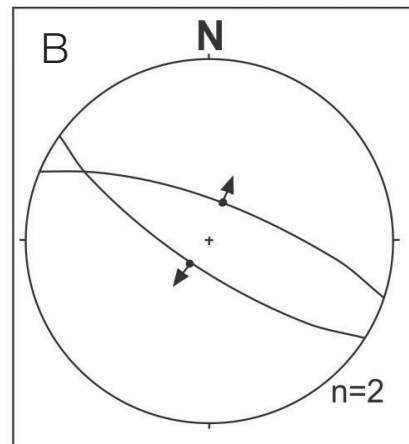

Formação Pimenteiras

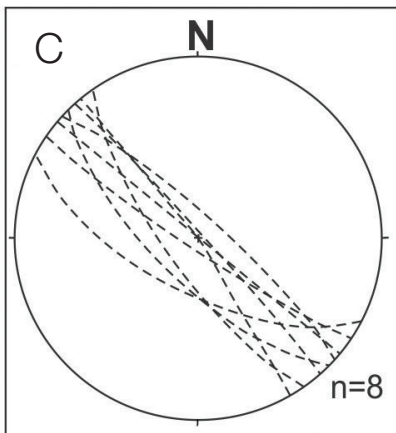

Grupo Serra Grande e Formação Pimenteiras

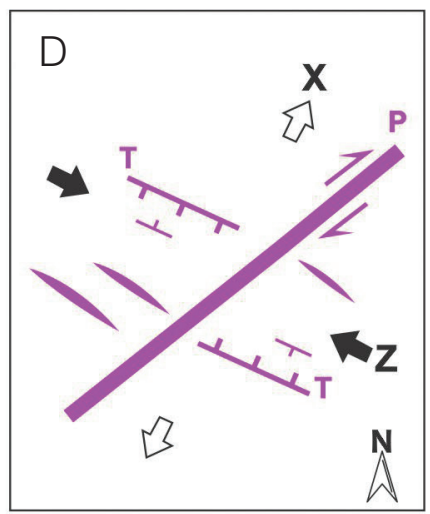

A

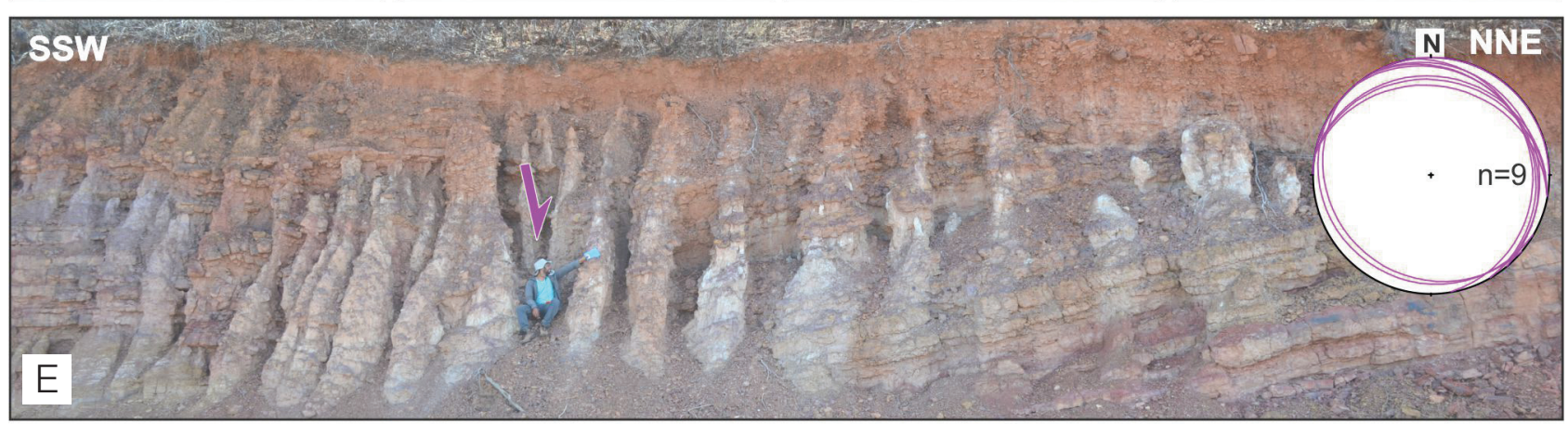

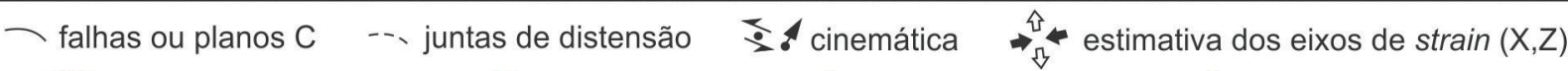
transcorrência dextral $(P) \quad Y$ falhas normais $(T)$ / juntas de distenção $(T)$ / / mergulho de camadas

Figura 9. De $(A)$ a $(C)$, projeções equiárea para falhas relacionadas à Deformação $D_{n+1}$. Em $(A)$, observa-se falhas transcorrentes destrais NE-SW. Em (B) e (E), são verificadas falhas normais e juntas de distensão (fraturas T) orientadas WNW a NW-SE. (D) representa as estruturas relacionadas ao evento $D_{n+1}$ em planta, com posicionamento estimado dos eixos de strain (X, estiramento; Z, encurtamento). Em (E), observa-se o basculamento do acamamento de litotipos da Formação Pimenteiras, relacionadas às falhas normais. 
Associadas às transcorrências, ocorrem falhas normais e juntas de distensão com orientação WNW-ESE a NW-SE (Figuras 9A, 9B e 9C).

Basculadas contra essas falhas normais, é comum encontrar, notadamente no setor sul da área, camadas das unidades paleozoicas mergulhando para NNE e SSW, em especial o GSG e a Formação Pimenteiras (projeção na Figura 9E).

A análise dos planos de falhas e juntas indica um campo de strain com eixo de encurtamento (Z) WNW-ESE e distensão (X) NNE-SSW horizontais, similares àqueles do evento deformacional $\mathrm{D}_{\mathrm{n}}$, todavia com pequena diferença angular em relação ao evento anterior (comparar as Figuras 8D e 9D).

Com base no modelo de Riedel, as falhas NE-SW podem ser interpretadas como estruturas paralelas às principais ou sintéticas do tipo R ou P, enquanto as falhas normais e juntas NW-SE representariam as fraturas T. Como a deformação afeta o GSG e a Formação Pimenteiras, pode-se inferir que o evento $\mathrm{D}_{\mathrm{n}+1}$ é de idade pós-devoniana. Modelo similar foi reportado por Destro et al. (1994) analisando estruturas análogas afetando o GSG na região de Santana do Acaraú, NW do Ceará, porém atribuindo às mesmas uma provável idade eocretácea. Por outro lado, Cacama et al. (2015) sugerem que o evento $\mathrm{D}_{\mathrm{n}+1}$ poderia ser mais antigo, seguramente pré-Eocretáceo, com base nas relações estruturais observadas na região NW do Ceará. A mesma conclusão é adotada no presente artigo.

\section{Deformação $D_{n+2}$}

Este evento deformacional, representado principalmente por falhas normais NE-SW com mergulho para NW ou SE, está impresso nas rochas sedimentares siluro-devonianas (Figuras 7, 10A, 10B, 10C e 10D). Este evento inclui, ainda, fraturas e juntas de distensão com orientação NE-SW (Figura 10E). Associados a esse evento (caracterizado por falhas normais e juntas distensionais), ocorrem, principalmente entre os municípios de Conceição do Canindé e Alegrete do Piauí, os enxames de diques básicos com direção NE-SW, que nessa região da bacia são correlacionados com a Suíte Sardinha, de idade eocretácea (Vaz et al., 2007) (Figuras 1, 6B, 6C, 7A e 7C). É comum encontrar arenitos do GSG apresentando silicificação atribuída a fluidos que percolaram ao longo das anisotropias das rochas, tais como acamamento, fraturas e contatos com diques (Figura 6C, 10A e 10C). Essas soluções podem ser responsáveis pela formação de cristas de arenitos silicificados, com orientação NE-SW (exemplo nas proximidades do município de Cajueiro/PI; Figura 6D). Especialmente no setor sul da área de trabalho, é frequente que as camadas do GSG exibam mergulhos para sudeste (Figuras 10F e 10G), portanto contrários ao que se espera para uma estrutura homoclinal suave mergulhando para o depocentro da bacia.

Esse conjunto de dados evidencia a importância dessas falhas normais de direção NE-SW, interceptando e basculando as camadas sedimentares - bem como o embasamento cristalino subjacente. A deformação é essencialmente cataclástica, similar àquela reportada por Cacama et al. (2015) no NW do Ceará. Todas essas estruturas são compatíveis com uma distensão NW-SE (Figura 10G), análoga à distensão eocretácea reconhecida nas Bacias Interiores do Nordeste do Brasil, ao leste da BPar (Matos, 1992, 1999; Sénant e Popoff, 1991; Córdoba et al., 2008).

\section{ESTRUTURAÇÃO DA BORDA SUDESTE DA BACIA NOS SETORES NORTE E SUL}

Os setores norte e sul da região estudada apresentam características distintas em termos geomorfológicos que podem ser reflexo da estruturação da borda da bacia em cada setor. Ainda que pesem outros fatores (e.g. paleorelevo, heterogeneidade de taxas de subsidência em diferentes regiões da bacia), a ausência de escarpa, a estreita faixa aflorante do GSG e da Formação Pimenteiras, bem como a grande frequência de fotolineamentos (falhas, diques e fraturas) com orientação NE-SW, apontam para forte controle estrutural sobre a morfologia atual da margem SE da bacia. Cabe ressaltar a diferença na estruturação das regiões escarpadas (entre Curimatá e São João do Piauí, setor sul) e aquelas sem escarpas (entre São João do Piauí e Alegrete do Piauí, setor norte). Em boa parte do setor norte, o contato entre o embasamento e os litotipos da bacia é expresso por falhas NE-SW, normalmente associadas a veios e brechas silicosas e diques de diabásio que ocorrem encaixados tanto no embasamento quanto nas rochas do GSG e da Formação Pimenteiras (além de outras unidades mais jovens, a oeste/NW da região deste estudo).

No setor sul, a não conformidade entre o embasamento e o GSG está bem preservada na base da escarpa, embora também possa estar seccionada por falhas NE-SW. Nessa região, morros vestigiais de arenitos do GSG encontram-se isolados no embasamento pela erosão neógena, em cotas mais elevadas que aquelas observadas na escarpa de borda da BPar (Figura 7D). O basculamento ou o arrasto de camadas do GSG e das formações sobrepostas estão associados a falhas normais do evento $D_{n+2}$.

Embora este estudo tenha focado na estruturação préneocretácea dessa borda da bacia, deve ser assinalada a necessidade de abordar a deformação mais recente, que controla a rede de drenagens na bacia e no seu entorno, bem como a história de epirogênese do Nordeste oriental 

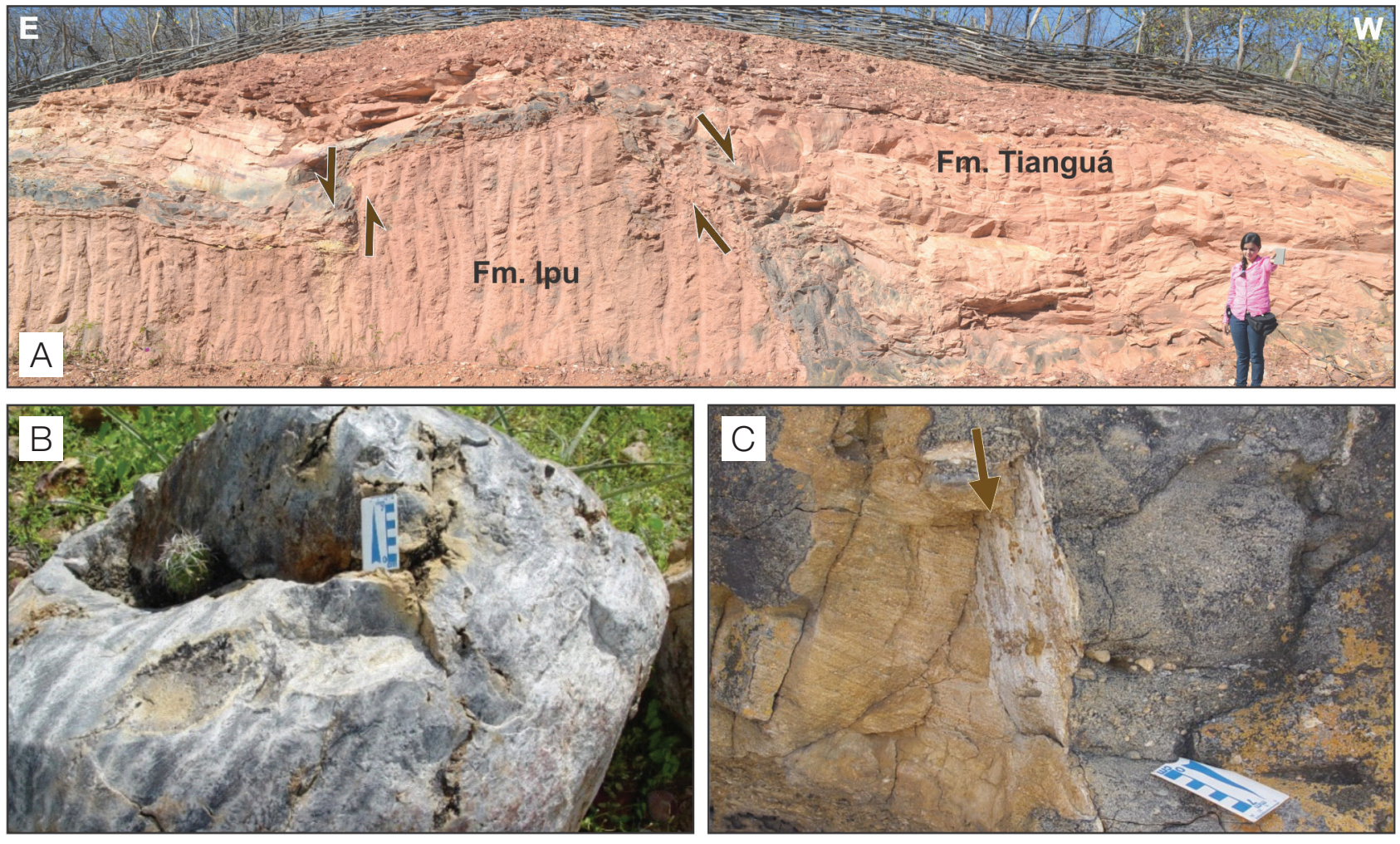

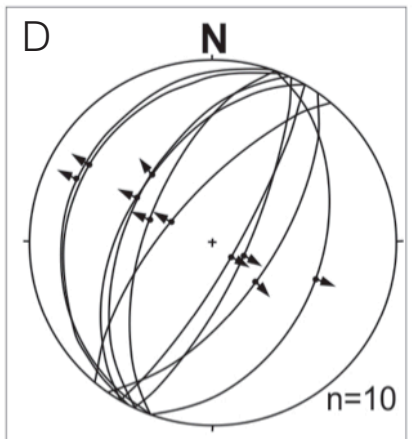

Grupo Serra Grande e Formação Cabeças

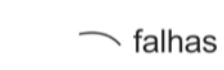

$\int$ diques básicos

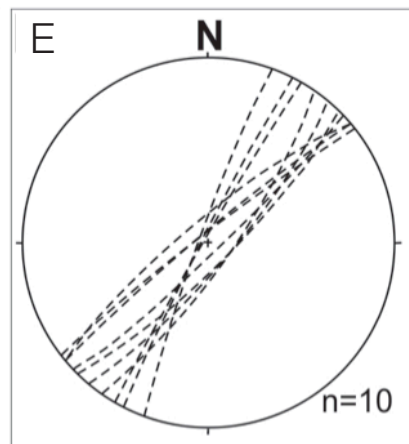

Grupo Serra Grande e Formação Pimenteiras

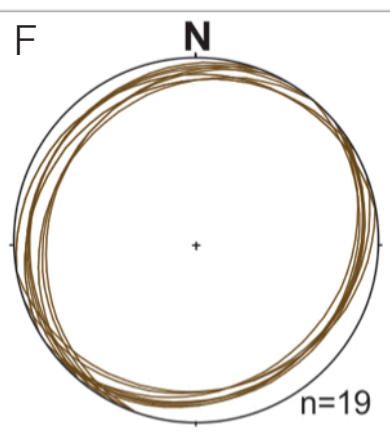

Grupo Serra Grande e Formação Pimenteiras

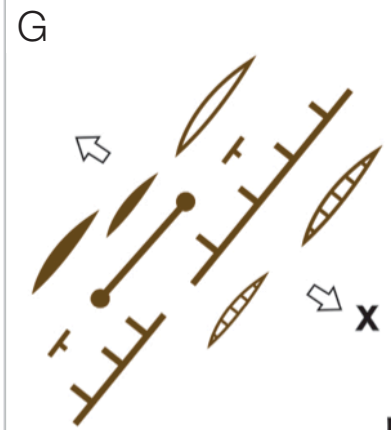

N

Figura 10. (A) Falhas normais afetando litotipos do Grupo Serra Grande a leste de Jaicós (PI). Observar a percolação de fluidos ao longo de descontinuidades (falhas e contato) em litotipos do Grupo Serra Grande; (B) Exemplo de veio silicoso ao longo de falhas nas proximidades do contato entre o Grupo Serra Grande e o embasamento. O "acamamento" de alto ângulo reflete a atuação de mecanismo crack-seal no seu alojamento. São comuns, nesses veios, feições de brechação; (C) Falha normal com slickenfibers silicosos de rake alto, em arenito do Grupo Serra Grande a SW de Patos do Piauí. Em (D) e (E), projeções equiárea para falhas relacionadas à Deformação $D_{n+2}$. Em (D), observa-se falhas normais com direção NE-SW. Em (E), as juntas de distensão também com orientação NE-SW. (F) ilustra o basculamento (ou "arrasto"; dobras de propagação de falhas) das camadas contra essas falhas normais. Em $(G)$, as estruturas relacionadas ao evento $D_{n+2}$ foram representadas em planta, com posicionamento estimado do eixo de estiramento X, com Z, encurtamento, vertical. 
brasileiro, que certamente influenciou na conformação da borda sudeste da BPar, a partir de uma herança estrutural do evento Brasiliano e de suas subsequentes reativações até o Eocretáceo.

\section{CONCLUSÕES}

O uso combinado de diversos métodos e ferramentas (Google Earth, Landsat 8 OLI e imagens de relevo sombreado, geradas a partir de imagens SRTM) e a aquisição de dados estruturais em campo permitiram realçar a trama estrutural frágil ou dúctil-frágil impressa nas rochas do embasamento Pré-Cambriano e das coberturas sedimentares siluro-devonianas da borda sudeste da BPar. Em relação aos mapeamentos prévios de Angelim et al. (2004), Vasconcelos et al. (2004) e Kosin et al. (2004), foram realizados ajustes cartográficos no contato entre o embasamento e o GSG, além de mapeamento de uma série de diques básicos paralelos à borda da bacia.

A interpretação das imagens dos sensores remotos permitiu reconhecer fotolineamentos tardios em relação à trama de alta temperatura das zonas de cisalhamento brasilianas do embasamento. Com base no registro estrutural observado das sequências molássicas brasilianas e nas idades referidas por Barroso et al. (2014) para o Grupo Jaibaras, esse evento dúctil-frágil $\mathrm{D}_{\mathrm{n}}$ pode ser posicionado no intervalo Ediacarano-Cambriano. Por outro lado, fotolineamentos associados a estruturas de caráter frágil, observados na cobertura sedimentar, foram associados a reativações póssilurianas de estruturas análogas ao LTB, que são também importantes ao longo dessa borda da bacia.

Boa parte dessas estruturas fanerozoicas está associada a falhas normais, em particular nas regiões sem escarpas (setor norte). No setor sul, entre os municípios de Curimatá e São João do Piauí, essas falhas e fraturas seccionam o contato em não conformidade entre o embasamento e a bacia, como evidenciado nas escarpas de arenitos da Formação Cabeças e do GSG.

Em adição à herança das zonas de cisalhamento brasilianas, a evolução tectônica da borda SE da BPar ocorreu em, pelo menos, três eventos deformacionais, designados $\mathrm{D}_{\mathrm{n}}$, $\mathrm{D}_{\mathrm{n}+1}$ e $\mathrm{D}_{\mathrm{n}+2}$. O primeiro evento deformacional corresponde a um estágio tardi-brasiliano, em que estruturas dúcteis do embasamento foram sucedidas por zonas de cisalhamento dúcteis-frágeis destrais, de direção NE-SW, e juntas distensionais/falhas normais E-W, nesta borda da bacia. Estruturas análogas foram descritas no Graben de Jaibaras, sendo atribuída uma idade edicarana-cambriana para as mesmas (Cacama et al., 2015).

$O$ evento $D_{n+1}$ reativou estruturas prévias do embasamento e afetou as unidades paleozoicas da bacia. A deformação resultante é dominada por estruturas transcorrentes destrais, com orientação similar ao evento $\mathrm{D}_{\mathrm{n}}$, evidenciando a reativação de herança estrutural do embasamento. Destro et al. (1994), Galvão (2002), Carvalho (2005) e Cacama et al. (2015) descreveram, na porção NE da bacia, nas adjacências do LTB, estruturas pós-devonianas com orientação e cinemática semelhantes àquelas do evento $\mathrm{D}_{\mathrm{n}+1}$ aqui reportado, afetando o GSG, o que também é observado no extremo sul da área abordada neste trabalho (região de Correntes (PI); Lima, 2016). O mesmo campo de deformação pode ter originado estruturas similares na porção sudeste da bacia, reaproveitando planos preexistentes com orientação similar àquela observada no LTB. Esse evento é seguramente de idade pré-eocretácea, ou mesmo pré-jurássica, uma vez que a sua cinemática é incompatível com aquela registrada nesses intervalos cronológicos (Jardim de Sá et al., 2015; Souza, 2016; Santos et al, 2016). Desse modo, esse evento deformacional deve ser mais antigo (eo- a mesopaleozoico) e pode estar relacionado a eventos colisionais no entorno do Atlântico Norte (Scotese, 2002).

As estruturas do evento deformacional $\mathrm{D}_{\mathrm{n}+2}$, que afeta tanto as sequências paleozoicas quanto o seu embasamento cristalino, na área de estudo, compreendem falhas e juntas distensionais com orientação NE-SW. Na área de estudo, esse evento é acompanhado pelo alojamento de diques básicos de provável idade eocretácea (Suite Sardinha; Vaz et al., 2007) e formação de veios silicosos associados a esse magmatismo. No NW do Ceará, a mesma cinemática é registrada em falhas que afetam tanto o Grupo Jaibaras quanto as unidades siluro-devonianas (Cacama et al., 2015). Essa distensão eocretácea, NW-SE, característica das Bacias Interiores do Nordeste do Brasil, é compatível com o rifteamento que deu origem ao Atlântico Sul.

\section{AGRADECIMENTOS}

A pesquisa teve apoio da CHEVRON/BRASIL que, em convênio com a Universidade Federal do Rio Grande do Norte (UFRN)/Programa de Pós-Graduação em Geodinâmica e Geofísica (PPGG)/Fundação Norte-Rio-Grandense de Pesquisa e Cultura (FUNPEC), financiou o projeto de pesquisa "Geologia e Sistemas Petrolíferos da Bacia Intracratônica do Parnaíba, Nordeste do Brasil".

\section{REFERÊNCIAS}

Abarca, M. A. A. (2006). Lineament extraction from digital terrain models: case study San Antonio del Sur area, Southeastern Cuba. XI Congresso Geológico Chileno, 2, 11-14, Antofagasta: International Institute for Aerospace Survey and Earth Observation (ITC). 
Almeida, F. F. M., Carneiro, C. D. R. (2004). Inundações marinhas fanerozóicas no Brasil e recursos minerais associados. In: V. Mantesso Neto, A. Bartorelli, C. D. R. Carneiro, B. B. Brito Neves (Eds.). Geologia do continente sul-americano: evolução da obra de Fernando Flávio Marques de Almeida. São Paulo: BECA. v. 1. p. 43-48.

Almeida, F. F. M., Hasui, Y., Brito-Neves, B. B., Fuck, R. A. (1981). Brazilian structural provinces: an introduction. Earth-Science Reviews, 17(1), 1-29.

Angelim, L. A. A., Vasconcelos, A. M., Gomes, J. R. C., Wanderley, A. A., Forgiarini, L. L., Medeiros, M. F. (2004). Folha SB-24-Jaguaribe. In: C. Schobbenhaus, J. H. Gonçalves, J. O. Santos, M. B. Abram, R. Leão Neto, G. M. M. Matos, R. M. M. Vidotti, A. B. Ramos (Eds.). Carta Geológica do Brasil ao Milionésimo, SIG. Programa Geologia do Brasil. Brasília: CPRM.

Antunes, A. F., Jardim de Sá, E. F., Nascimento da Silva, C. C., Lira Lins, F. A. P. (2016). Interpretação Sismoestrutural da Porção Central da Bacia do Parnaíba (NE do Brasil). XLVIII Congresso Brasileiro de Geologia. Porto Alegre: Sociedade Brasileira de Geologia - SBG. Disponível em: <http://sbg. sitepessoal.com/anais48cbg $>$. Acesso em: 5 jan. 2017.

Antunes, A. F., Silva, C. C. N., Jardim de Sá, E. F., Lira Lins, F. A. P., Córdoba, V. C., Sousa, D. C., Alves da Silva, F. C. (2015). Expressão Sísmica do Lineamento Transbrasiliano na Porção Sul-Sudoeste da Bacia do Parnaíba. XXVI Simpósio de Geologia do Nordeste. Natal: Sociedade Brasileira de Geologia - Núcleo NE. p. 192. Disponível em: <http://www. ccet.ufrn.br/26sgne/Livro_de_Resumos-XXVISGNE.pdf $>$. Acesso em: 5 jan. 2017.

Barroso, F. R. G., Viana, M. S. S., Lima Filho, M. F., Agostinho, S. M. O. (2014). First Ediacaran Fauna Occurrence in Northeastern Brazil (Jaibaras Basin, ?Ediacaran-Cambrian): Preliminary Results and Regional Correlation. Anais da Academia Brasileira de Ciências, 86(3), 1029-1042.

Cacama, M. S. J. B., Jardim de Sá, E. F., Alves da Silva, F. C., Lira Lins, F. A. P. (2015). Assinatura estrutural e geofísica da Porção Norte (fronteira Ceará-Piauí) do Lineamento Transbrasiliano: reativação na Bacia do Parnaíba. Geologia USP. Série Cientifica, 15(3-4), 67-81.

Carvalho, J. A. A. (2005). Caracterização macro, meso e microscópica das estruturas frágeis do corpo arenitico conglomerático da Região de Santana do Acaraú (CE) e seu embasamento circundante. Dissertação (Mestrado). Natal: Centro de Ciências Exatas e da Terra - UFRN.
Castro, D. L., Bezerra, F. H. R., Fuck, R. A., Vidotti, R. M. (2016). Geophysical evidence of pre-sag rifting and postrifting fault reactivation in the Parnaíba Basin, Brazil. Solid Earth, 7, 529-548.

Castro, D. L., Fuck, R. A., Phillips, J. D., Vidotti, R. M., Bezerra, F. H. R., Dantas, E. L. (2014). Crustal structure beneath the Paleozoic Parnaíba Basin revealed by airborne gravity and magnetic data, Brazil. Tectonophysics, 614, 128-145.

Chamani, M. A. C. (2011). Tectônica Intraplaca e Deformação Sinsedimentar Induzida por Abalos Sísmicos: o Lineamento Transbrasiliano e Estruturas Relacionadas na Província Parnaiba, Brasil. Dissertação (Mestrado). São Paulo: Instituto de Geociências - USP.

Chamani, M. A. C. (2015). Tectônica Sinsedimentar no Siluro-devoniano da Bacia do Parnaíba, Brasil: O Papel de Grandes Estruturas do Embasamento na Origem e Evolução de Bacias Intracratônicas. Tese (Doutorado). São Paulo: Instituto de Geociências - USP.

Cordani, U. G., Brito Neves, B. B., Fuck, R. A., Porto, R., Thomaz-Filho, A., Cunha, F. M. B. (2009). Estudo preliminar de integração do Pré-cambriano com eventos tectônicos das bacias sedimentares brasileiras (Republicação). Boletim de Geociências da Petrobras, 17(1), 133-204.

Cordani, U. G., Pimentel, M. M., Ganade de Araújo, C. E., Fuck, R. A. (2013). The significance of the TransbrasilianoKandi tectonic corridor for the amalgamation of West Gondwana. Brazilian Journal of Geology, 43(3), 583-597.

Córdoba, V. C., Antunes, A. F., Jardim De Sá, E. F., Silva, A. N., Sousa, D. C., Lins, F. A. P. L. (2008). Análise estratigráfica e estrutural da Bacia do Rio do Peixe, Nordeste do Brasil: integração de dados a partir do levantamento sísmico pioneiro 0295_rio_do_peixe_2d. Boletim de Geociências da Petrobras, 16, 53-68.

Daly, M. C., Andrade, V., Chuck, A. B., Costa, R., McDowell, K., Piggott, N., Poole, A. J. (2014). Brasiliano crustal structure and the tectonic setting of the Parnaíba Basin of NE Brazil: Results of a deep seismic reflection profile. Tectonics, 33, 2102-2120.

Destro, N., Szatmari, P., Ladeira, E. A. (1994). Post-Devonian transpressional reactivation of a Proterozoic ductile shear zone in Ceará, NE Brazil. Journal of Structural Geology, 16(1), 35-45.

Freitas, M. S. (2014). Carta Geológica de Parnaguá. Folha SC.23-Z-A-I. Escala 1:100.000. Teresina: Serviço Geológico do Brasil/CPRM. 
Fuck, R. A., Dantas, E. L., Vidotti, R. M., Roig, H. L., Almeida, T. (2013). Deformação Intracontinental em Sistemas Transcorrentes: O caso do Lineamento Transbrasiliano: Geometria, Idade e Significado. XIV Simpósio Nacional de Estudos Tectônicos, CD-ROM. Chapada dos Guimarães: SBG.

Galvão, C. C. (2002). Mapeamento geológico estrutural da Região Nordeste de Santana do Acaraú-CE, com ênfase na deformação frágil. Relatório de graduação. Natal: Centro de Ciências Exatas e da Terra - UFRN.

Ganas, A., Pavlides, S., Karastathis, V. (2005). DEM-based morphometry of range-front escarpments in Attica, central Greece, and its relation to fault slip rates. Geomorphology, 65(3-4), 301-319.

Gilluly, J. (1976). Lineaments: Ineffective guides to ore deposits. Economic Geology, 71, 1507-1514.

Góes, A. M., Souza, J. M. P., Teixeira, L. B. (1990). Estágio Exploratório e Perspectivas Petrolíferas da Bacia do Parnaíba. Boletim de Geociências da Petrobras, 4(1), 55-64.

Góes, A. M. O. (1995). Formação Poti (carbonifero inferior) da Bacia do Parnaíba. Tese (Doutorado). São Paulo: Instituto de Geociências - USP.

Jardim de Sá, E. F., Amaro, V. E., Holanda, M. H. B. M., Duarte, M. I. M. (1993). Mapeamento por sensores remotos das estruturas transcorrentes/transpressionais brasilianas na Faixa Seridó, NE do Brasil. VII Simpósio Brasileiro de Sensoriamento Remoto, 221-225. Curitiba.

Jardim de Sá, E. F., Antunes, A. F., Nascimento da Silva, C. C., Sousa, D. C., Lira Lins, F. A. P., Alves da Silva, F. C., Lima, F. G. G., Moreira, J. A. M., Nascimento, M. A. L., Carneiro, M. S., Córdoba, V. C., Souza, Z. S. (2015). Arcabouço e Evolução Tectônica da Bacia do Parnaíba. XXVI Simpósio de Geologia do Nordeste. Natal: Sociedade Brasileira de Geologia - Núcleo NE. p. 3-5. Disponível em: <http://www. ccet.ufrn.br/26sgne/Livro_de_Resumos-XXVISGNE.pdf $>$. Acesso em: 5 jan. 2017.

Kellndorfer, J., Walker, W., Pierce, L., Dobson, C., Fites, J. A., Hunsaker, C., Vona, J., Clutter, M. (2004). Vegetation height estimation from Shuttle Topography Mission and National Elevation Datasets. Remote sensing of Environment, 93, 339-358.

Kosin, M., Angelim, L. A. A., Souza, J. D., Guimarães, J. T., Teixeira, L. R., Martins, A. A. M., Bento, R. V., Santos, R. A., Vasconcelos, A. M., Neves, J. P., Wanderley, A. A., Carvalho, L. M., Pereira, L. H. M., Gomes, I. P. (2004). Folha Aracaju SC.24. In: C. Schobbenhaus, J. H. Gonçalves, J. O. S. Santos, M. B. Abram, R. Leão Neto, G. M. M. Matos, R. M. Vidotti, M. A.
B. Ramos, J. D. A. Jesus (Eds.). Carta Geológica do Brasil ao Milionésimo, SIG. Programa Geologia do Brasil. Brasília: CPRM.

Lima, F. G. F. (2016). Interpretação de Lineamentos Estruturais na Borda Sudeste da Bacia do Parnaíba. Dissertação (Mestrado). Natal: Programa de Pós-Graduação em Geodinâmica e Geofísica - UFRN.

Lima, T. P. C. (2015). Expressão Geofísica-Estrutural do Lineamento Transbrasiliano na Porção Central da Bacia do Parnaíba (Maranhão-Piauí). Dissertação (Mestrado). Natal: Centro de Ciências Exatas e da Terra - UFRN.

Matos, R. M. D. (1992). The Northest Brasilian Rift System. Tectonics, 11(4), 776-791.

Matos, R. M. D. (1999). History of the northeast Brazilian rift system: kinematic implications for the break-up between Brazil and West Africa. In: N. R. Cameron, R. H. Bate, V. S. Clure (Eds.). The oil and gas habitats of the South Atlantic. London: Geological Society of London. v. 153. p. 55-73.

Milani, E. J., Thomaz Filho, A. (2000). Sedimentary basins of South America. In: U. G. Cordani, E. J. Milani, A. Thomaz Filho, D. A. Campos (Eds.). Tectonic evolution of South America. Rio de Janeiro: Academia Brasileira de Ciências e Departamento Nacional da Produção Mineral. v. 1. p. 389-449.

Morais Neto, J. M., Trodstorf Jr., I., Santos, S. F., Vasconcelos, C. S., Menezes, J. R. C., Ribas, M. P., Iwata, S. A. (2013). Expressão sísmica das reativações tectônicas do Lineamento Transbrasiliano na Bacia do Parnaíba. XIV Simpósio Nacional de Estudos Tectônicos / VIII International Symposium on Tectonics, CD-ROM. Chapada dos Guimarães: SBG.

Nunes, K. C. (1993). Interpretação integrada da Bacia do Parnaíba com ênfase nos dados aeromagnéticos. III Congresso Internacional da Sociedade Brasileira de Geofísica, 152157. Rio de Janeiro: SBGf.

Oguchi, T., Aoki, T., Matsuta, N. (2003). Identification of an active fault in the Japanese Alps from DEM-based hill shading. Computers \& Geosciences, 29(7), 885-891.

O’Leary, D. W., Friedman, J. D., Pohn, H. A. (1976). Lineament, linear, lineation: some proposed new standards for old terms. GSA Bulletin, 87, 1463-1469.

Oliveira, D. C., Mohriak, W. U. (2003). Jaibaras through: an important element in the early tectonic evolution of the Parnaíba interior sag basin, Northern Brazil. Marine and Petroleum Geology, 20, 351-383. 
Onorati, G., Ventura, R., Poscolieri, M., Chiarini, V., Crucilla, U. (1992). The Digital Elevation Model of Italy for geomorphology and structural geology. CATENA, 19(2), 147-178.

Parente, C. V., Silva Filho, W. F., Almeida, A. R. (2004). Bacias do Estágio de Transição do Domínio Setentrional da Província Borborema. In: V. Mantesso Neto, A. Bartorelli, C. D. R. Carneiro, B. B. Brito-Neves (Eds.). Geologia do Continente Sul-Americano: Evolução da Obra de Fernando Flávio Marques de Almeida, v. 1, 525-536. São Paulo: BECA.

Pedreira, A. J., Lopes, R. C., Vasconcelos, A. M., Bahia, R. B. C. (2003). Bacias Sedimentares Paleozóicas e MesoCenozóicas. In: L. A. Bizzi, C. Schobbenhaus, R. M. Vidotti, J. H. Gonçalves (Eds.). Geologia, Tectônica e Recursos Minerais do Brasil. Brasília: UnB. v. 1. p. 55-85.

Pedrosa Jr., N. C., Vidotti, R. M., Fuck, R. A., Oliveira, K. M. L., Castelo Branco, R. M. G. (2014). Structural framework of the Jaibaras Rift, Brazil, based on geophysical data. Journal of South American Earth Sciences, 1-17. DOI: 10.1016/j. jsames.2014.07.005

Sachs, L. L. B., Batista, I. H., Brilhante, J. R., Braga, I. F., Amaral, E. S., Leitão, G. V. (2015). Projeto avaliação dos depósitos de opalas de Pedro II: Estado do Piauí. Teresina: CPRM. (Série Pedras Preciosas, 8).

Santos, C. H. O., Jardim de Sá, E. F., Alves da Silva, F. C. (2015). Expressão Estrutural do Lineamento Transbrasiliano na Porção Sul-Sudoeste da Bacia do Parnaíba. XXVI Simpósio de Geologia do Nordeste, 191. Natal: Sociedade Brasileira de Geologia - Núcleo NE. Disponível em: <http://www. ccet.ufrn.br/26sgne/Livro de Resumos-XXVISGNE.pdf $\$$. Acesso em: 7 jan. 2017.

Santos, R. D., Castro, D. L., Bezerra, F. H. R., Vidotti, R. M., Fuck, R. A., Dantas, E. L., Lima, T. P. C. (2013). Influência do Lineamento Transbrasiliano na formação do arcabouço estrutural da Bacia Parnaíba. XIII International Congress of the Brazilian Geophysical Society, 1-6. Rio de Janeiro: SBGf.
Schobbenhaus, C., Gonçalves, J. H., Santos, J. O. S., Abram, M. B., Leão Neto, R., Matos, G. M. M., Vidotti, R. M., Ramos, M. A. B. (2004). Carta Geológica do Brasil ao Milionésimo: Sistema de Informações Geográficas - SIG e 46 folhas na escala 1:1.000.000. Brasília: CPRM.

Scotese, C. R. (2002). PALEOMAP Project. Disponível em: $<$ http://www.scotese.com>. Acesso em: 9 jan. 2017.

Sénant, J., Popoff, M. (1991). Early Cretaceous extension in northeast Brazil related to the South Atlantic opening. Tectonophysics, 198, 35-46.

Souza, K. S. (2016). Análise Estrutural do Sistema de Grabens do Rio Tocantins, Borda Oeste da Bacia do Parnaíba (Tocantins, Pará e Maranhão). Dissertação (Mestrado). Natal: Programa de Pós-Graduação em Geodinâmica e Geofísica - UFRN.

Spisila, A. L. (2011). Análise Estrutural do Intervalo Permiano-Jurássico da Bacia do Parnaíba - região de Araguaina (TO). Dissertação (Mestrado). Curitiba: Programa de Pós-Graduação em Geologia - UFPR.

Vasconcelos, A. M., Kosin, M., Souza, J. D. de, Valente, C. R., Neves, J. P., Heineck, C. A., Lacerda Filho, J. V., Teixeira, L. R., Borges, V. P., Bento, R. V., Guimarães, J. T., Neves, J. P., Oliveira, I. W. B., Gomes, I. P., Malouf, R. F., Carvalho, L. M. de, Abreu Filho, W. (2004). Folha SC.23 Rio São Francisco. In: C. Schobbenhaus, J. H. Gonçalves, J. O. S. Santos, M. B. Abram, R. Leão Neto, G. M. M. Matos, R. M. Vidotti, M. A. B. Ramos, J. D. A. de Jesus (Eds.). Carta Geológica do Brasil ao Milionésimo, SIG. Programa Geologia do Brasil. Brasília: CPRM.

Vaz, P. T., Rezende, N. G. A. M., Wanderley Filho, J. R., Travassos, W. A. S. (2007). Bacia do Parnaíba. Boletim de Geociencias da Petrobras, 15(2), 253-263.

Zalán, P. V. (2004). Evolução Fanerozóica das Bacias Sedimentares Brasileiras. In: V. Mantesso Neto, A. Bartorelli, C. D. R. Carneiro, B. B. Brito-Neves, B.B. (Eds.). A geologia do continente Sul-americano: Evolução da Obra de Fernando Flávio Marques de Almeida. São Paulo: BECA. v. 1. p. 555-613. 